\title{
New acremonium-like taxa in the Bionectriaceae and Plectosphaerellaceae
}

\author{
Alejandra Giraldo ${ }^{1,2,3}$, Josepa Gené ${ }^{1, *}$, Deanna A. Sutton ${ }^{2}$, \\ Nathan Wiederhold ${ }^{2}$, Josep Guarro ${ }^{1}$ \\ ${ }^{1}$ Unitat de Micologia, Facultat de Medicina i Ciències de la Salut and IISPV, Universitat Rovira i \\ Virgili, C/ Sant Llorenç 21, 43201 Reus, Tarragona, Spain. \\ ${ }^{2}$ CBS-KNAW Fungal Biodiversity Centre, Uppsalalaan 8, 3584 CT Utrecht, The Netherlands \\ ${ }^{3}$ Department of Microbiology and Plant Pathology, Forestry and Agricultural Biotechnology \\ Institute (FABI), University of Pretoria, Pretoria 0002, South Africa \\ ${ }^{4}$ Fungus Testing Laboratory, University of Texas Health Science Center, San Antonio, Texas, \\ USA.
}

*Corresponding author: Josepa Gené, e-mail address: josepa.gene@urv.cat

Abstract Several molecular studies have demonstrated that species traditionally assigned to the form genus Acremonium are polyphyletic, while Acremonium sensu stricto is a central element of the Bionectriaceae (Hypocreales). Based on phenotypic characters and molecular phylogenetic analyses, two new Acremonium species, $A$. moniliforme and $A$. dimorphosporum, are described. The former is related to Emericellopsis and is characterized by cylindrical conidia, acicular phialides and abundant moniliform hyphae. Acremonium dimorphosporum resembles Acremonium borodinense. It produces cylindrical, smooth-walled and ellipsoidal, rough-walled conidia. The new genus Brunneomyces is proposed based on three species, including $B$. brunnescens (formerly A. brunnescens), B. europaeus and B. hominis. All of them are characterized by brown hyphae, sympodial conidiophores and chains of ovoidal to ellipsoidal conidia. Also, the proposed new species Chordomyces albus is characterized by its light-coloured colonies, simple or branched conidiophores, phialides with percurrent proliferations and cylindrical collarettes, and ellipsoidal to cylindrical conidia. The combined analysis of the LSU, ITS, $R P B 2$ and TEF1- $\alpha$ loci supports the inclusion of $B$. brunnescens, $B$. europaeus, $B$. hominis and C. albus in Plectosphaerellaceae. 
Key words Emericellopsis, Hypocreales, Plectosphaerellaceae, Phylogeny, Taxonomy

\section{Introduction}

Acremonium accommodates saprobic species that can colonize diverse substrates (Gams 1971, 1975; Domsch et al. 2007), important plant pathogens (Alfaro-García et al. 1996; Lin et al. 2004) or agents of opportunistic infections in humans (Summerbell 2003; Guarro 2012; de Hoog et al. 2015). Species-level identifications in Acremonium is difficult on the basis of morphological characters because their asexual structures are poorly differentiated. Molecular phylogenetic analyses have demonstrated that the genus is polyphyletic. Recent phylogenetic studies have shown that Acremonium species cluster in different lineages throughout the Ascomycota, mainly in the Sordariomycetes (Glenn et al. 1996; Zare et al. 2007; Schoch et al. 2009; Gräfenhan et al. 2011; Perdomo et al. 2011; Summerbell et al. 2011; Giraldo et al. 2012, 2015). Epitypification of the type species of the genus, $A$. alternatum, linked Acremonium sensu stricto to the Bionectriaceae (Hypocreales) (Summerbell et al. 2011), which also accommodates several other, partly teleomophically typified genera with an acremonium-like anamorph, such as Emericellopsis, Hapsidospora, Nigrosabulum, Bulbithecium and Mycoarachis (Gams 1971; Summerbell et al. 2011). Other species of Acremonium are distantly related to the type species of the genus and belong to the Glomerellales or other families of the Hypocreales (Zare et al. 2007; Gräfenhan et al. 2011; Carlucci et al. 2012; Giraldo et al. 2012; Grum-Grzhimaylo 2013a; Maharachchikumbura et al. 2015, 2016; Lombard et al. 2015).

In a previous study on Acremonium species from clinical samples in USA (Perdomo et al. 2011), some of the isolates distributed in different groups within the Hypocreales (informally named groups $\mathrm{J}$ and $\mathrm{N}$ ) and Plectosphaerellaceae (groups $\mathrm{Q}$ and $\mathrm{R}$ ), could not be identified. The taxonomy of those isolates and of other Acremonium species in Plectosphaerellaceae was resolved in the present study by using multilocus DNA sequence analyses and phenotypic methods. 


\section{Materials and methods}

\section{Fungal isolates and sequences}

The fungi included in this study are shown in Table 1. Six clinical isolates provided by the Fungus Testing Laboratory at the University of Texas Health Science Center (UTHSC) were tentatively identified as $A$. hyalinulum and previously linked to Hypocreales or Plectosphaerellaceae (Perdomo et al. 2011). In addition, one Acremonium isolate (FMR 11785) obtained from soil with the procedure described in Giraldo et al. (2012), and five ex-type or reference strains provided by the CBS-KNAW Fungal Biodiversity Centre (CBS) were also included in our study. Numerous DNA sequences of Acremonium species and related genera reported in different studies (Sigler et al. 2004; Zuccaro et al. 2004; Zare et al. 2007; Summerbell et al. 2011; Carlucci et al. 2012; GrumGrzhimaylo et al. 2013a,b, 2016; Giraldo et al. 2014) were retrieved from public databases (Table 2) and included in the phylogenetic analyses.

\section{Phenotypic studies}

Morphological features were examined on potato dextrose agar (PDA; Pronadisa, Madrid, Spain) and oatmeal agar (OA; filtered oat flakes after $1 \mathrm{~h}$ of simmering, $30 \mathrm{~g}$; agar, $20 \mathrm{~g}$; distilled water to final volume of $1000 \mathrm{~mL}$ ). Cultures were incubated at $25{ }^{\circ} \mathrm{C}$ in the dark for $4 \mathrm{wk}$. Colony diameters were measured after 14 days of incubation and the colony colour rated after Kornerup and Wanscher (1978). Microscopic features were examined and measured from cultures grown on $\mathrm{OA}$ under an Olympus $\mathrm{CH}-2$ light microscope (Olympus Corporation, Tokyo, Japan) from direct wet mounts with either $85 \%$ lactic acid or Shear's solution, or from slide cultures. At least 30 randomly selected elements were measured for each structure using an ocular micrometer. Photomicrographs were obtained with a Zeiss Axio-Imager M1 light microscope (Zeiss, Oberkochen, Germany), using phase contrast and Nomarski differential interference. The ability of the fungi to grow at 4, 12, 15, 20, 25, 30, $32,35,37$ and $40{ }^{\circ} \mathrm{C}$ was determined on PDA in duplicate. 
Table 1 Isolates included in this study

\begin{tabular}{|c|c|c|c|c|c|c|c|c|c|}
\hline \multirow[t]{2}{*}{ Species } & \multirow[t]{2}{*}{ Strain $^{a}$} & \multirow[t]{2}{*}{ Origin $^{b}$} & \multirow{2}{*}{$\begin{array}{l}\text { Previous } \\
\text { identification }^{c}\end{array}$} & \multicolumn{5}{|c|}{ GenBank accession number $^{d}$} & \multirow[t]{2}{*}{ Reference } \\
\hline & & & & LSU & ITS & BT2 & TEF1- $\alpha$ & RPB2 & \\
\hline $\begin{array}{l}\text { Acremonium } \\
\text { dimorphosporum } \\
\text { (=Acremonium sp. II) }\end{array}$ & $\begin{array}{l}\text { UTHSC 08-3639 } \\
\text { (= CBS 139050, } \\
\text { FMR 10548) }\end{array}$ & BAL, USA & $\begin{array}{l}\text { Acremonium sp. } \\
(\text { Group J) }\end{array}$ & LN810506 & LN810515 & - & - & - & This study \\
\hline \multirow{2}{*}{$\begin{array}{l}\text { Acremonium } \\
\text { moniliforme } \\
(=\text { Acremonium sp. I) }\end{array}$} & $\begin{array}{l}\text { FMR } 11785^{\top}(= \\
\text { CBS 139051) }\end{array}$ & Soil, Spain & Acremonium sp. & LN810507 & LN810516 & LN810523 & LN810531 & LN810525 & This study \\
\hline & $\begin{array}{l}\text { UTHSC 08-2284 } \\
\text { (= FMR 10363) }\end{array}$ & Toe nail, USA & $\begin{array}{l}\text { Acremonium sp. } \\
(\text { Group N) }\end{array}$ & LN810508 & LN810517 & LN810524 & LN810532 & LN810526 & This study \\
\hline $\begin{array}{l}\text { Acremonium } \\
\text { stromaticum }\end{array}$ & CBS $863.73^{\top}$ & $\begin{array}{l}\text { Root and rhizome of } \\
\text { Musa sapientum, } \\
\text { Honduras }\end{array}$ & A. stromaticum & HQ232143 & DQ825969 & - & LN810533 & - & $\begin{array}{l}\text { Summerbell et al. (2011), } \\
\text { this study }\end{array}$ \\
\hline $\begin{array}{l}\text { Brunneomyces } \\
\text { brunnescens }\end{array}$ & CBS $559.73^{\top}$ & $\begin{array}{l}\text { On dead stem of } \\
\text { Dendrocalamus } \\
\text { giganteus, Sri Lanka }\end{array}$ & A. brunnescens & HQ231966 & LN810520 & - & LN810534 & - & $\begin{array}{l}\text { Summerbell et al. (2011), } \\
\text { this study }\end{array}$ \\
\hline \multirow[t]{2}{*}{$\begin{array}{l}\text { Brunneomyces } \\
\text { hominis }\end{array}$} & $\begin{array}{l}\text { UTHSC 06-415 } \\
\text { (= CBS 139053, } \\
\text { FMR 10429) }\end{array}$ & Sputum, USA & $\begin{array}{l}\text { A. hyalinulum } \\
\text { (Group Q) }\end{array}$ & LN810509 & KP131517 & - & LN810535 & - & $\begin{array}{l}\text { Irinyi et al. (2015), this } \\
\text { study }\end{array}$ \\
\hline & $\begin{array}{l}\text { UTHSC R-3853 } \\
(=\text { CBS 139054, } \\
\text { FMR 10437) }\end{array}$ & Sputum, USA & $\begin{array}{l}\text { A. hyalinulum } \\
\text { (Group Q) }\end{array}$ & LN810510 & KP131518 & - & LN810536 & - & $\begin{array}{l}\text { Irinyi et al. (2015), this } \\
\text { study }\end{array}$ \\
\hline \multirow[t]{2}{*}{$\begin{array}{l}\text { Brunneomyces } \\
\text { europaeus }\end{array}$} & CBS 560.86 & $\begin{array}{l}\text { Leaf of Bambusa } \\
\text { sp., France }\end{array}$ & $\begin{array}{l}\text { A. hyalinulum } \\
\text { (Group Q) }\end{array}$ & LN810511 & LN810518 & - & LN810537 & LN810527 & This study \\
\hline & CBS $652.96^{\top}$ & $\begin{array}{l}\text { River sediment, } \\
\text { Spain }\end{array}$ & A. hyalinulum & LN810512 & LN810519 & - & LN810538 & LN810528 & This study \\
\hline \multirow[t]{2}{*}{ Chordomyces albus } & CBS $987.87^{\top}$ & $\begin{array}{l}\text { On Hypogymnia } \\
\text { physodes, } \\
\text { Luxembourg }\end{array}$ & A. antarcticum & JX158444 & DQ825970 & - & JX158400 & JX158466 & $\begin{array}{l}\text { Grum-Grzhimaylo et al. } \\
\text { (2013a), Zare et al. } \\
\text { (2007), this study }\end{array}$ \\
\hline & $\begin{array}{l}\text { UTHSC 06-874 } \\
\text { (= FMR 10433) }\end{array}$ & Sputum, USA & $\begin{array}{l}\text { Acremonium sp. } \\
\text { (Group R) }\end{array}$ & LN810513 & LN810521 & - & LN810539 & LN810529 & This study \\
\hline $\begin{array}{l}\text { Chordomyces } \\
\text { antarcticus }\end{array}$ & $\begin{array}{l}\text { UTHSC 08-3693 } \\
\text { (= CBS 139055; } \\
\text { FMR 10549) }\end{array}$ & Nail, USA & $\begin{array}{l}\text { Acremonium sp. } \\
\text { (Group R) }\end{array}$ & LN810514 & LN810522 & - & LN810540 & LN810530 & This study \\
\hline
\end{tabular}

a CBS, CBS-KNAW Fungal Biodiversity Centre, Utrecht, the Netherlands; FMR, Faculty of Medicine Reus, Spain; UTHSC, Fungus Testing Laboratory, University of Texas Health Science Center, San Antonio, Texas, USA; ${ }^{\top}$ Type strain. ${ }^{b}$ BAL, Bronchoalveolar lavage fluid. ${ }^{\mathrm{C}}$ Identification in Perdomo et al. (2011). ${ }^{d}$ Accession numbers of sequences newly generated in this study are indicated in boldface. LSU large subunit of the nrDNA; ITS internal transcribed spacer regions of the nrDNA and intervening $5.8 \mathrm{~S}$ nrDNA; BT2 beta-tubulin gene; TEF1- $\alpha$ transcription elongation factor 1-alpha; RPB2 RNA polymerase II second largest subunit. 
Table 2 Taxa used in the phylogenetic analyses with their GenBank accession numbers

\begin{tabular}{|c|c|c|c|c|c|c|c|}
\hline \multirow[t]{2}{*}{ Species } & \multirow[t]{2}{*}{ Strain $^{a}$} & \multicolumn{5}{|c|}{ GenBank accession number ${ }^{b}$} & \multirow[t]{2}{*}{ Reference } \\
\hline & & LSU & ITS & BT2 & TEF1- $\alpha$ & RPB2 & \\
\hline Acremonium alcalophilum & CBS 114.92 & JX158443 & DQ825967 & - & JX158399 & JX158465 & $\begin{array}{l}\text { Zare et al. (2007), Grum- } \\
\text { Grzhimaylo et al. (2013a) }\end{array}$ \\
\hline Acremonium alternatum & CBS $407.66^{\prime}$ & HQ231988 & - & - & - & - & Summerbell et al. (2011) \\
\hline Acremonium biseptum & CBS $750.69^{\prime}$ & HQ231998 & - & - & - & - & Summerbell et al. (2011) \\
\hline Acremonium borodinense & CBS $101148^{\prime}$ & HQ232003 & - & - & - & - & Summerbell et al. (2011) \\
\hline Acremonium brachypenium & CBS $866.73^{\prime}$ & HQ232004 & - & - & - & - & Summerbell et al. (2011) \\
\hline Acremonium camptosporum & CBS $756.69^{\top}$ & HQ232008 & - & - & - & - & Summerbell et al. (2011) \\
\hline Acremonium cerealis & CBS 207.65 & HQ232013 & - & - & - & _- & Summerbell et al. (2011) \\
\hline Acremonium charticola & CBS $117.25^{\prime}$ & HQ232016 & - & - & - & - & Summerbell et al. (2011) \\
\hline \multirow{2}{*}{ Acremonium citrinum } & CBS $384.96^{\prime}$ & HF680217 & HF680236 & - & - & _- & Giraldo et al. (2014) \\
\hline & CBS 758.69 & HQ232012 & HF680222 & - & - & - & $\begin{array}{l}\text { Summerbell et al. (2011), } \\
\text { Giraldo et al. (2014) }\end{array}$ \\
\hline Acremonium collariferum & CBS 124585 & FJ765364 & - & - & - & - & Weisenborn et al. (2010) \\
\hline Acremonium flavum & CBS $596.70^{\prime}$ & HQ232037 & - & - & - & - & Summerbell et al. (2011) \\
\hline \multirow[t]{2}{*}{ Acremonium fuci } & CBS 113889 & HQ232038 & AY632652 & - & - & - & $\begin{array}{l}\text { Zuccaro et al. (2004), } \\
\text { Summerbell et al. (2011) }\end{array}$ \\
\hline & CBS $112868^{\prime}$ & - & AY632653 & AY632690 & - & - & Zuccaro et al. (2004) \\
\hline Acremonium furcatum & CBS $122.42^{\top}$ & EF543831 & AY378154 & - & - & - & Zare et al. (2007) \\
\hline \multirow[t]{3}{*}{ Acremonium fusidioides } & CBS 705.86 & HF680218 & HF680237 & - & - & - & Giraldo et al. (2014) \\
\hline & CBS $840.68^{\top}$ & HQ232039 & FN706542 & - & - & - & $\begin{array}{l}\text { Perdomo et al. (2011), } \\
\text { Summerbell et al. (2011) }\end{array}$ \\
\hline & UTHSC 08-1455 & HF680216 & HF680235 & - & - & _- & Giraldo et al. (2014) \\
\hline Acremonium gamsii & CBS $726.71^{\top}$ & HQ232040 & - & - & - & - & Summerbell et al. (2011) \\
\hline Acremonium guillematii & CBS $766.69^{\prime}$ & HQ232042 & - & - & - & - & Summerbell et al. (2011) \\
\hline Acremonium hennebertii & CBS $768.69^{\top}$ & HQ232044 & HF680238 & - & - & - & $\begin{array}{l}\text { Summerbell et al. (2011), } \\
\text { Giraldo et al. (2014) }\end{array}$ \\
\hline
\end{tabular}


Acremonium nigrosclerotium Acremonium parvum

Acremonium persicinum Acremonium pilosum

Acremonium pinkertoniae Acremonium potronii Acremonium pseudozeylanicum Acremonium pteridii Acremonium radiatum Acremonium recifei

Acremonium restrictum Acremonium roseolum Acremonium rutilum

Acremonium salmoneum

Acremonium sclerotigenum Acremonium sordidulum Acremonium spinosum Acremonium tectonae Acremonium thermophilum Acremonium tubakii

Acremonium verruculosum Acremonium vitellinum Acremonium zonatum Acremonium sp.

Acremonium sp.

Acrostalagmus annulatus Acrostalagmus luteoalbus Chordomyces antarcticus

Emericellopsis alkalina
CBS $154.72^{\prime}$ CBS 381.70A '

HQ232069
HQ231986

CBS 831.97

CBS 310.59

CBS $124.70^{\top}$

CBS 125.70

CBS 511.82

CBS 157.70

CBS $379.70 \mathrm{~F}$

CBS 560.73

CBS 782.69

CBS 142.62

CBS $137.35^{\prime}$

CBS 362.76

CBS 178.40

CBS $289.62^{\top}$

CBS $396.66^{\top}$

CBS $721.71^{\top}$

JS-NJ01 *

CBS 124.42

CBS 385.73

CBS 136.33

CBS $725.87^{\top}$

CBS 734.71

CBS $790.69^{\top}$

CBS 111360

CBS $989.69^{\prime}$

CBS $792.69^{\prime}$

CBS 565.67

A104 *

A105 *

A106 *

A107 *

A108 *

A110 *

A111 *

E102*

FMR 11780

DAOM 212126

CBS 194.87

CBS 120042

CBS $120045^{\top}$

CBS 137610

A124 *

A118 *

HQ231989

HQ232077

HF680209

HF680210

HF680207

HQ232089

HQ232102

HQ232104

HQ232106

HQ232108

HQ232119

HQ232123

HQ232124

HQ232125

HQ232136

HQ232137

HQ232144

HQ232145

HQ232148

HQ232151

HQ232155

$-$

KJ807179

GU180646

EF543826

KJ443108

KJ443109

KJ443106
AY632654 AY632689
HF

HF680226

AY632655

$-$

$-$

$-$

$-$

AY

$-$

KC987141

KC987142

KC987143

KC987144

KC987145

KC987147

KC987148

KC987172

-

GU180632

-

KJ443240

KJ443241

KJ443238

KC987161

KC987155
$-$
Summerbell et al. (2011)

Summerbell et al. (2011), Giraldo et al. (2014)

Summerbell et al. (2011)

Summerbell et al. (2011)

Giraldo et al. (2014)

Giraldo et al. (2014)

Giraldo et al. (2014)

Summerbell et al. (2011)

Zuccaro et al. (2004)

Summerbell et al. (2011)

Summerbell et al. (2011)

Summerbell et al. (2011)

Summerbell et al. (2011)

Summerbell et al. (2011)

Summerbell et al. (2011)

Summerbell et al. (2011)

Summerbell et al. (2011)

Summerbell et al. (2011)

Unpublished

Summerbell et al. (2011)

Summerbell et al. (2011)

Summerbell et al. (2011)

Summerbell et al. (2011)

Summerbell et al. (2011)

Summerbell et al. (2011)

Zuccaro et al. (2004)

Summerbell et al. (2011)

Summerbell et al. (2011)

Summerbell et al. (2011)

KC987103 KC998963 KC999001

KC987104 KC998964 KC999002

KC987105 KC998965 KC999003

KC987106 KC998966 KC999004

KC987107 KC998967 KC999005

KC987109 KC998969 KC999007

KC987110 KC998970 KC999008

KC987134 KC998994 KC999030

GU180662

$-$

KJ443196 KJ443156

KJ443197 KJ443157

KJ443194 KJ443154

KC987123 KC998983 KC999020

KC987123 KC998983 KC999020
KC987117 KC998977 KC999014

Grum-Grzhimaylo et al. (2013b)

Grum-Grzhimaylo et al. (2013b)

Grum-Grzhimaylo et al. (2013b)

Grum-Grzhimaylo et al. (2013b)

Grum-Grzhimaylo et al. (2013b)

Grum-Grzhimaylo et al. (2013b)

Grum-Grzhimaylo et al. (2013b)

Grum-Grzhimaylo et al. (2013b)

Crous et al. (2015)

Réblová et al. (2011)

Zare et al. (2007)

Grum-Grzhimaylo et al. (2016)

Grum-Grzhimaylo et al. (2016)

Grum-Grzhimaylo et al. (2016)

Grum-Grzhimaylo et al. (2013b)

Grum-Grzhimaylo et al. (2013b) 
Emericellopsis donezkii Emericellopsis glabra

Emericellopsis humicola

Emericellopsis maritima

Emericellopsis microspora

Emericellopsis minima

Emericellopsis mirabilis

Emericellopsis pallida

Emericellopsis robusta

Emericellopsis salmosynnemata

Emericellopsis stolkiae

Emericellopsis synnematicola

Emericellopsis terricola

Gibellulopsis piscis

Gibellulopsis nigrescens

Gliocladium cibotii

Gliomastix polychromum

Gliomastix roseogrisea

Leucosphaerina arxil

Linkosia fusiformis

Musicillium theobromae

Niesslia exilis

Phialemonium atrogriseum

Plectosphaerella cucumerina

Sarocladium bacillisporum

Sarocladium bactrocephalum

Sarocladium glaucum
CBS $127350^{\prime}$

CBS 120049

CBS 120043

CBS 120044

CBS $489.71^{\top}$

CBS $119.40^{\top}$

CBS $180.56^{\top}$

CBS $491.71^{\top}$

CBS $380.622^{\prime}$

CBS 190.55

CBS 871.68

CBS 111361

CBS 177.53

CBS $490.71^{\top}$

CBS 624.73

CBS 489.73

CBS 382.62

CBS $159.71^{\top}$

CBS $176.60^{\top}$

CBS $120.40^{\top}$

CBS 229.59

CCF 3815

NRRL 54109

CBS 892.70

CBS 101221

CBS $109240{ }^{\prime}$

CBS $181.27^{\prime}$

CBS 134.56

CBS $737.84^{\top}$

HKUCC 10824

CBS 385.32

CBS 458.51

CBS $968.72^{\top}$

CBS 357.70

CBS 604.67

CBS $137.37^{\top}$

DAOM 226828

Plect 170 *

CBS 425.67

CBS $749.69^{\prime}$

CBS $796.69^{\prime}$

$-$

$-$

$-$

$-$

U57082

-

EF543835

EF543840

EF543842

HQ232091

HQ232121

HQ232159

DQ408571

EF543836

EF543837

EF543838

AY489718

HQ231981

JF780520

GU180647

HQ239032

HE608658

HQ231994

HE608657
KC987171 KC987170 KC987168 KC987169

AY632658

AY632657

AY632659

AY632670

AY632663 AY632669

AY632660

AY632661

AY632656

KC987176

AY632667

AY632664

AY632666

AY632668

AY632665

U57676

AY632662

FJ430737

HQ698592

DQ825985

EF543848

DQ825980 $-$

$-$

$-$

EF543858

$-$

JF780522

GU180630

HQ238991

$-$
KC987133 KC998993 KC999029 Grum-Grzhimaylo et al. (2013b) KC987132 KC998992 KC999028 Grum-Grzhimaylo et al. (2013b) KC987130 KC998990 KC999026 Grum-Grzhimaylo et al. (2013b) KC987131 KC998991 KC999027 Grum-Grzhimaylo et al. (2013b)

AY632674

AY632673 - _ _ _ Z Zuccaro et al. (2004)

AY632675 - _ _ _ Z Zuccaro et al. (2004)

AY632686 FJ238393 KC999033 Zuccaro et al. (2004), Schoch et al. (2009), Grum-Grzhimaylo et al. (2013b)

Zuccaro et al. (2004)

AY632679

Zuccaro et al. (2004), GrumGrzhimaylo et al. (2013b)

AY632676 KC998996 KC999032 Zuccaro et al. (2004), Grum-

Grzhimaylo et al. (2013b)

$\begin{array}{llll}\text { AY632677 } & - & - & \text { Zuccaro et al. (2004) } \\ - & - & - & \text { Zuccaro et al. (2004) }\end{array}$

KC987138 KC998998 KC999034 Grum-Grzhimaylo et al. (2013b)

AY632683

AY632680

AY632682

AY632684

AY632681

AY632678

$-$

$-$

$-$

$-$

$-$

$-$

$-$

$-$

$-$

$-$

$-$

$-$

Zuccaro et al. (2004)

Zuccaro et al. (2004)

Zuccaro et al. (2004)

Zuccaro et al. (2004)

Zuccaro et al. (2004)

Glenn et al. (1996)

Zuccaro et al. (2004)

Hujslová et al. (2009)

Unpublished

Zare et al. (2007)

Zare et al. (2007)

Zare et al. (2007)

Summerbell et al. (2011)

Summerbell et al. (2011)

Summerbell et al. (2011)

Shenoy et al. (2006)

Zare et al. (2007)

Zare et al. (2007)

Zare et al. (2007)

Castlebury et al. (2004)

Summerbell et al. (2011)

Carlucci et al. (2012)

GU180663 Réblová et al. (2011)

Summerbell et al. (2011),

Carlucci et al. (2012)

Giraldo et al. (2012)

Summerbell et al. (2011)

Giraldo et al. (2012) 
Sarocladium kiliense Sarocladium ochraceum

Sarocladium oryzae

Sarocladium strictum

Sarocladium terricola

Sarocladium zeae

Selinia pulchra

Sodiomyces alkalinus

Sodiomyces magadii

Sodiomyces tronii

Stanjemonium grisellum

Stanjemonium ochroroseum

Stilbella fimetaria

Verrucostoma freycinetiae

Verticillium albo-atrum

Verticillium dahliae

\begin{tabular}{|c|c|c|}
\hline CBS $122.29^{\prime}$ & HQ232052 & - \\
\hline CBS $428.67^{\prime}$ & HQ232070 & - \\
\hline CBS $180.74^{\prime}$ & HQ232166 & - \\
\hline CBS $346.70^{\top}$ & HQ232141 & - \\
\hline CBS $243.59^{\top}$ & HQ232046 & - \\
\hline CBS $801.69^{\top}$ & HQ232152 & - \\
\hline AR 2812 * & 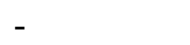 & HM484859 \\
\hline CBS $110278^{\top}$ & JX158427 & JX158405 \\
\hline CBS 132731 & JX158428 & JX158406 \\
\hline CBS $137619^{\prime}$ & KJ443148 & KJ443278 \\
\hline CBS $137618^{\prime}$ & KJ443147 & KJ443277 \\
\hline CBS137620 & KJ443149 & KJ443279 \\
\hline CBS $655.79^{\prime}$ & - & AY632671 \\
\hline CBS $656.79^{\prime}$ & - & AY632672 \\
\hline DAOM 229279 & HQ232176 & - \\
\hline D99026 * & - & AY952467 \\
\hline $\mathrm{MH} 178$ * & - & FJ430712 \\
\hline SES201* & - & FJ939394 \\
\hline MAFF 240100 & - & HM484866 \\
\hline CBS $130.51^{\top}$ & HQ231976 & DQ825977 \\
\hline DL-II & DQ4 & - \\
\hline & U1 & \\
\hline
\end{tabular}

$\begin{array}{lll}- & - & - \\ - & - & - \\ - & - & - \\ - & - & - \\ - & - & - \\ - & - & -\end{array}$

HM484884 HM484841 JX158383 JX158449 X158384 JX158450

$-$ AY632687 AY632688 -

-

$-$

$-$

$-$

-
-
-
-
-
-
JX158449
JX158450
-
-
-
-
-
-
-
-
-
-

Summerbell et al. (2011)

Summerbell et al. (2011)

Summerbell et al. (2011)

Summerbell et al. (2011)

Summerbell et al. (2011)

Summerbell et al. (2011)

Chaverri et al. (2011)

Grum-Grzhimaylo et al. (2913a)

Grum-Grzhimaylo et al. (2913a)

Grum-Grzhimaylo et al. (2016)

Grum-Grzhimaylo et al. (2016)

Grum-Grzhimaylo et al. (2016)

Zuccaro et al. (2004)

Zuccaro et al. (2004)

Summerbell et al. (2011)

Lehr et al. (2006)

Hujslová et al. (2009)

Mazzaferro et al. (2010)

Chaverri et al. (2011)

Zare et al. (2007), Summerbell

et al. (2011)

Spatafora et al. (2006)

Rehner \& Samuels (1995)

Castlebury et al. (2004),

Spatafora et al. (2007)

\footnotetext{
${ }^{a}$ AFTOL, Assembling the Fungal Tree of Life project; ATCC, American Type Culture Collection, Manassas, Virginia, USA; CBS, CBS-KNAW Fungal Biodiversity Centre, Utrecht, the Netherlands; CCF, Culture Collection of Fungi, Department of Botany, Faculty of Science, Charles University, Prague, Czech Republic; DAOM, Plant Research Institute, Department of Agriculture (Mycology), Ottawa, Canada; FMR, Faculty of Medicine Reus, Spain; HKUCC, Hong Kong University Culture Collection, Department of Ecology and Biodiversity, Hong Kong, China; NRRL, Agricultural Research Service Culture Collection, National Center for Agricultural Utilization Research, US Department of Agriculture, Peoria, Illinois, USA; MAFF, Ministry of Agriculture, Forestry and Fisheries, Tsukuba, Ibaraki, Japan; UAMH, University of Alberta Microfungus Collection and Herbarium; Edmonton, Canada; UTHSC, Fungus Testing Laboratory, University of Texas Health Science Center, San Antonio, Texas, USA; ${ }^{\top}$ Type strain; ${ }^{*}$ from GenBank. ${ }^{b}$ LSU large subunit of the nrDNA; ITS internal transcribed spacer regions of the nrDNA and intervening 5.8S nrDNA; BT2 beta-tubulin gene; TEF1- $\alpha$ transcription elongation factor 1-alpha; RPB2 RNA polymerase II second largest subunit.
} 


\section{DNA extraction, amplification and sequencing}

Total genomic DNA was extracted from fresh colonies using PrepMan Ultra Sample Preparation Reagent (Applied Biosystems, Foster City, CA, USA), following the manufacturer's protocol. The DNA was quantified using a NanoDrop 3000 fluorospectrometer (Thermo Scientific, Asheville, NC, USA). The internal transcribed spacer (ITS) regions and the 5 ' end of the 28S nrDNA gene (LSU) were amplified and sequenced with the primer pairs ITS5/ITS4 (White et al. 1990) and LROR/LR5 (Vilgalys and Hester 1990; Vilgalys and Sun 1994), respectively. Fragments of the translation elongation factor 1-alpha (TEF1- $\alpha$ ), RNA polymerase II second largest subunit (RPB2) and $\beta$-tubulin (BT2) genes were amplified with the following primer sets: EF 983F/EF 2218R (Rehner and Buckley 2005) for TEF1- $\alpha$, RPB2-5F/RPB2-7R (Liu et al. 1999) for RPB2 and Bt1a/Bt1b (Glass and Donaldson 1995) for BT2 using PCR protocols described elsewhere (Zuccaro et al. 2004; Grum-Grhimaylo et al. 2013a). PCR products were purified and sequenced at Macrogen Europe (Amsterdam, The Netherlands) with the same primers used for amplification. The program SeqMan v. 7.0.0 (DNASTAR, Madison, WI, USA) was used to obtain consensus sequences of each isolate.

\section{Phylogenetic analysis}

Phylogenetic analyses based on LSU sequences determined relatedness of taxa to either the " $J$ and N" groups of the Hypocreales or to the " $Q$ and $R$ " groups of the Plectosphaerellaceae. Subsequently, several multilocus sequence analyses for each particular clade were performed to confirm the results obtained with the LSU data. ITS, BT2, RPB2 and TEF1- $\alpha$ loci were used for the isolate of the group N; ITS and LSU for the group J; and ITS, LSU, RPB2 and $T E F 1-\alpha$ for the isolates included in groups $Q$ and $R$. Sequences were aligned and concatenated in MEGA v. 6.06 (Tamura et al. 2013) using the Clustal W and MUSCLE applications (Thompson et al. 1994; Edgar 2004). Manual corrections of the alignments, selection of the best-fit nucleotide substitution models for each locus and for the combined dataset, and Maximum Composite Likelihood (ML) phylogenetic analyses were performed in MEGA 6.06. Gaps or missing data were treated as partial deletion with a site coverage cut-off of $95 \%$ and Nearest-Neighbor-Interchange (NNI). The internal branch support was 
assessed by a search of 1000 bootstrapped data sets. A bootstrap support (BS) $\geq 70$ was considered as statistically significant. Phylogenetic distance values among isolates were estimated with Kimura 2-parameter as nucleotide substitution model under the same software. A second phylogenetic reconstruction via Bayesian inference $(\mathrm{BI})$ was done using MrBayes v. 3.2.1 (Ronquist and Huelsenbeck 2003; Ronquist et al. 2012). Markov chain Monte Carlo (MCMC) sampling was performed with two simultaneous runs for 3 million generations, with samples taken every 100 generations. Bayesian posterior probabilities (PP) were obtained from the $50 \%$ majority-rule consensus tree after removing the first $25 \%$ of the collected trees. A PP value $\geq 0.95$ was considered statistically significant. The best nucleotide substitution model for each gene in the Bayesian analysis $(G T R+G+I)$ was determined using MrModelTest v. 2.3 (Nylander 2004). Congruency of the sequence datasets for the separate loci were determined using tree topologies of $70 \%$ reciprocal Neighbour-Joining (NJ) bootstrap trees with Maximum Likelihood distances for identifying topology conflict visually (Gueidan et al. 2007). Because no incongruence was observed, the different matrices were combined in the final phylogenetic analyses. All novel DNA sequences were deposited in GenBank (Table 1), the alignments and the resulting trees in TreeBASE (http://www.treebase.org), and taxonomic novelties in MycoBank (http://www.MycoBank.org; Crous et al. 2004).

\section{Results}

The phylogenetic analysis based on LSU sequences of the isolates UTHSC 082284 (group N), UTHSC 08-3639 (group J) and FMR 11785 together with hypocrealean Acremonium species and related genera reported by Summerbell et al. (2011) is shown in the Figure 1. The final tree is based on 75 aligned sequences, 847 characters including gaps, of which 580 were conserved, 267 were variable and 195 were phylogenetically informative. Tamura-Nei with gamma distribution $(\mathrm{TN}+\mathrm{G})$ and the general time reversible with gamma distribution and a portion of invariable sites $(G T R+G+l)$ were found as the bestfit nucleotide substitution models for $\mathrm{ML}$ and $\mathrm{BI}$, respectively. The phylogenetic 
tree revealed that the isolates clustered in the "Emericellopsis" and "fusidioides" clades (Bionectriaceae) as defined by Summerbell et al. (2011). The isolates UTHSC 08-2284 and FMR 11785 fell into the Emericellopsis clade (BS = 98 \%, $\mathrm{PP}=1.00$ ) together with the type species of Emericellopsis, E. terricola (CBS 120.40), A. exuviarum (UAMH 9995), A. fuci (CBS 113889) and A. salmoneum (CBS 721.71). The two mentioned unidentified isolates showed identical sequences and were grouped in a highly supported subclade (Acremonium sp. I). The isolate UTHSC 08-3639 (Acremonium sp. II) was represented by a single branch, phylogenetically related $(\mathrm{BS}=83 \%, \mathrm{PP}=1.0)$ to $A$. fusidioides, $A$. hennebertii and the recently described species $A$. citrinum, $A$. parvum and $A$. pilosum (Giraldo el al. 2014), all belonging to the fusidioides clade (Fig. 1).

To better resolve the phylogenetic relationships obtained from the LSU analyses of Acremonium sp. I and Acremonium sp. II, a multilocus study was performed for each of the unidentified species and their respective closely related species. The first one (Fig. 2) was based on ITS, BT2, RPB2 and TEF1$\alpha$ sequences and targeted the two isolates of Acremonium sp. I, members of the Emericellopsis clade, and additional species previously reported to be related to Emericellopsis (Sigler et al. 2004; Zuccaro et al. 2004, Grum-Grzhimaylo et al. 2013b) such as Stanjemonium grisellum, S. ochroroseum and Acremonium potronii. The data set included 48 sequences of different strains and 2807 characters (2004 conserved, 803 variables and 604 phylogenetically informative). Verrucostoma freycinetiae and Selinia pulchra were used as outgroup. Tamura 3-parameter with gamma distribution $(T 92+G)$ and $G T R+G+1$ were found to be the best nucleotide substitution models for $\mathrm{ML}$ and $\mathrm{BI}$, respectively. The trees generated by using $\mathrm{ML}$ and $\mathrm{BI}$ had a similar topology. The phylogenetic tree was consistent with previously reported phylogenies (Sigler et al. 2004; Zuccaro et al. 2004; Grum-Grzhimaylo et al. 2013b). The two isolates of Acremonium sp. I formed a highly supported basal clade (BS $=84 \%$, $\mathrm{PP}=1.00)$, distant from the species of Acremonium, Emericellopsis and Stanjemonium. Acremonium sp. I is described below as a new species, named Acremonium moniliforme. 


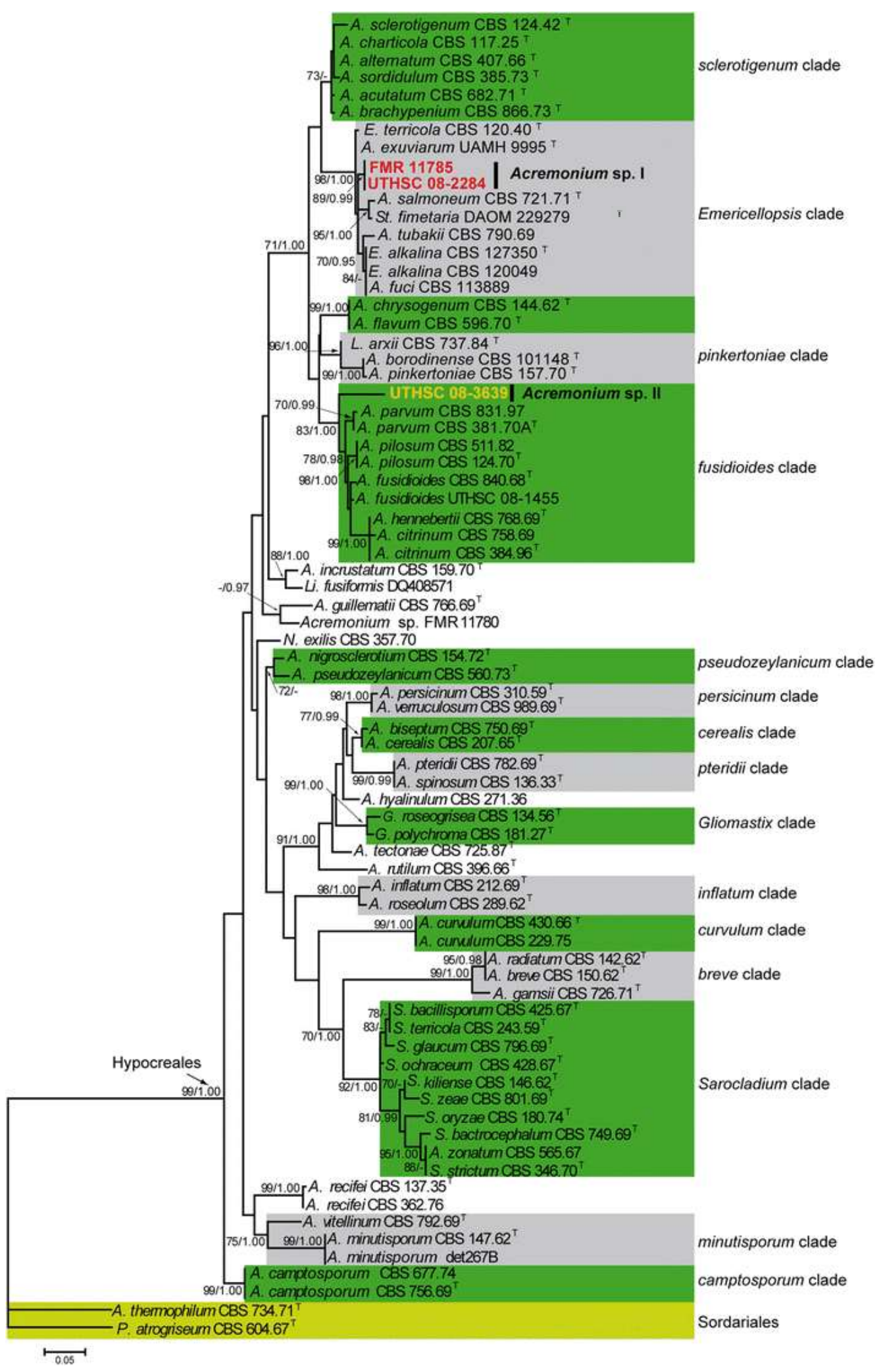

Fig. 1 Maximum composite likelihood tree based on analyses of partial LSU sequences of selected genera of the Hypocreales including Acremonium (abbreviated as A.), Emericellopsis (E.), Gliomastix (G.), Leucosphaerina (L.), Linkosia (Li.), Niesslia (N.), Phialemonium (P.), Sarocladium (S.) and Stilbella (St.). Clade names are based on Summerbell et al. (2011). Bootstrap support values above 70\%/ Bayesian posterior probability values above 0.95 are shown at the nodes. ${ }^{\mathrm{T}}$, Type strain. Acremonium sp. I represents newly described $A$. moniliforme and Acremonium sp. II, A. dimorphosporum 


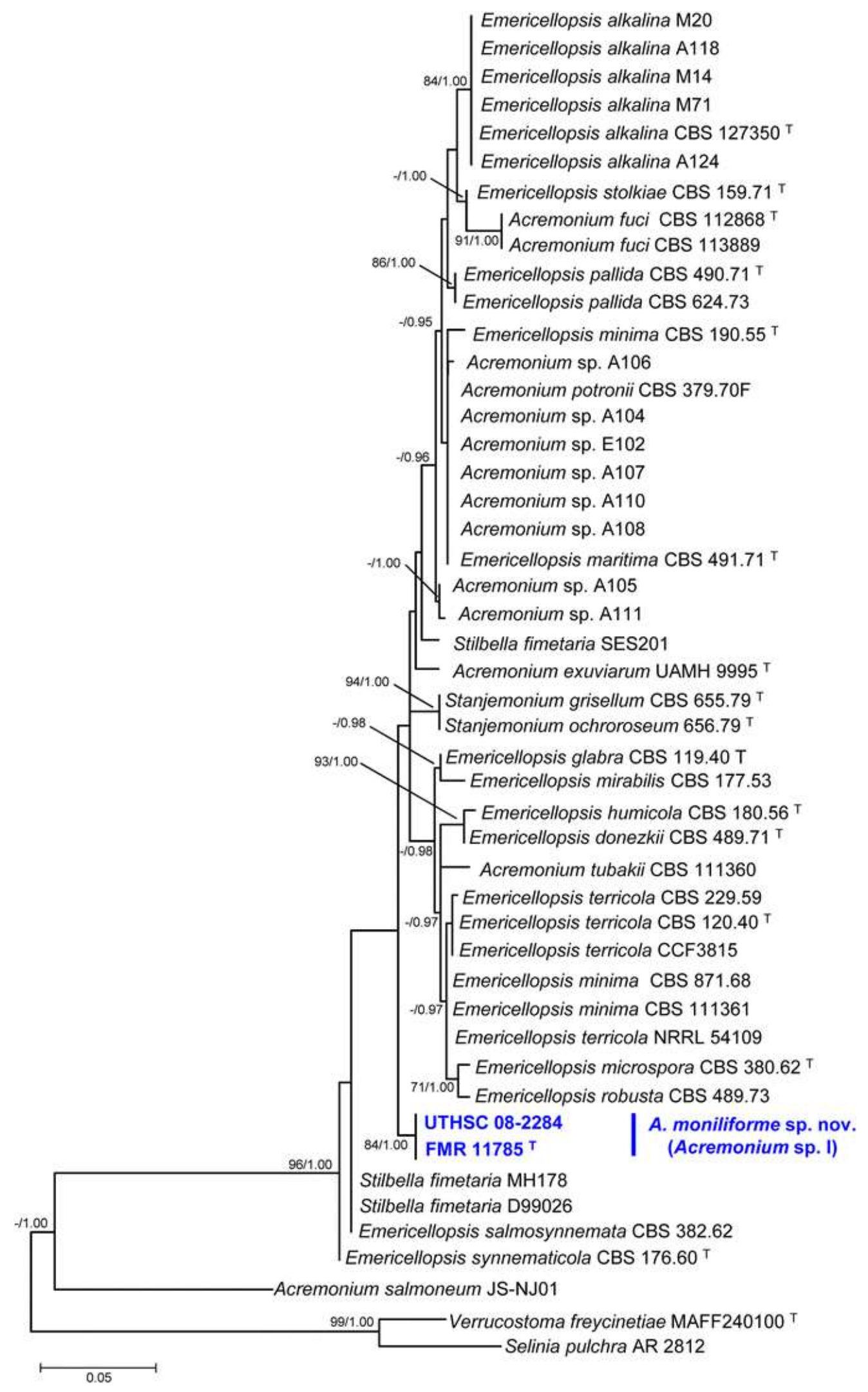

Fig. 2 Maximum composite likelihood tree based on sequences of ITS and partial protein encoding genes (BT2, RPB2 and TEF1- $\alpha$ ) of selected acremonium-like taxa of the Bionectriaceae. Bootstrap support values above $70 \%$ / Bayesian posterior probability values above 0.95 , are shown at the nodes. ${ }^{\top}$, Type strain 


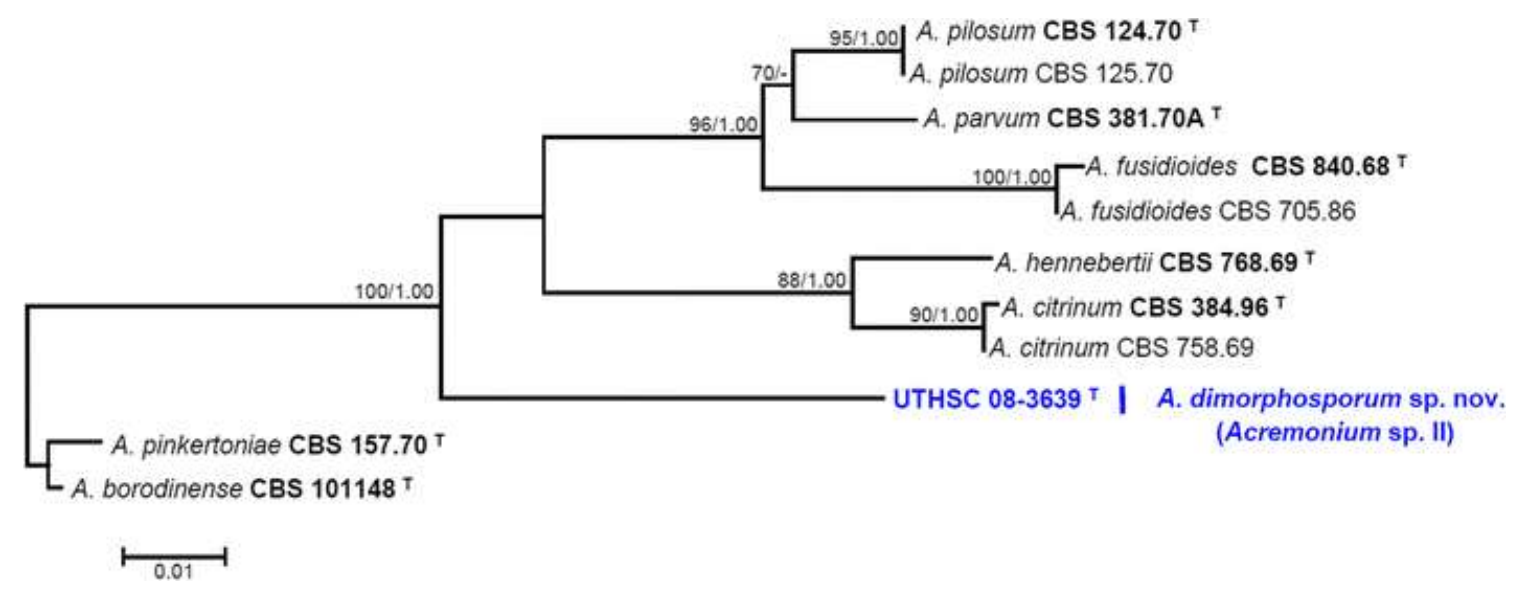

Fig. 3 Maximum composite likelihood tree based on sequences of ITS and partial LSU genes from $A$. dimorphosporum and species of the fusidioides clade. Bootstrap support values above $70 \%$ / Bayesian posterior probability values above 0.95 , are shown at the nodes. ${ }^{\top}$, Type strain

The other analysis (Fig. 3) included a combination of the ITS and LSU sequences of Acremonium sp. II and the ex-type and reference strains of the Acremonium species from the fusidioides clade. The data set consisted of 11 sequences of different strains and 915 characters (731 conserved, 184 variable and 135 phylogenetically informative). The ex-type strains of Acremonium pinkertoniae and $A$. borodinense were used as outgroup. $\mathrm{ML} / \mathrm{BI}$ analyses were done with Kimura-two parameter with gamma distribution $(K 2+G)$ as the best-fit nucleotide substitution model. In this analysis, Acremonium sp. II clustered distantly from Acremonium species forming dimorphic conidia ( $A$. fusidioides, $A$. pilosum and $A$. borodinense) and other species with elongate conidia in chains (A. hennebertii, A. parvum and A. citrinum). Acremonium sp. II is proposed as a new species, $A$. dimorphosporum.

The phylogenetic reconstruction using the LSU, ITS, TEF1- $\alpha$ and RPB2 loci from the clinical isolates of the groups Q (UTHSC 06-415 and UTHSC R-3853) and R (UTHSC 06-874 and UTHSC 08-3693), and other representative species of the Plectosphaerellaceae (Fig. 4) is based on a combined dataset consisting of 3271 characters, including 805 phylogenetically informative positions (135 LSU, 151 ITS, 158 TEF1- $\alpha$ and 361 RPB2), and 39 strains or taxa including the outgroup Colletotrichum orbiculare and $C$. lagerarium. The best-fit nucleotide substitution model for $\mathrm{ML}$ and $\mathrm{BI}$ analysis was $\mathrm{K} 2+\mathrm{G}$. The phylogenetic tree showed that the isolates UTHSC 06-874 and UTHSC 08-3693 clustered in Chordomyces (Grum-Grzhimaylo et al. 2016). While UTHSC 08-3693 was 


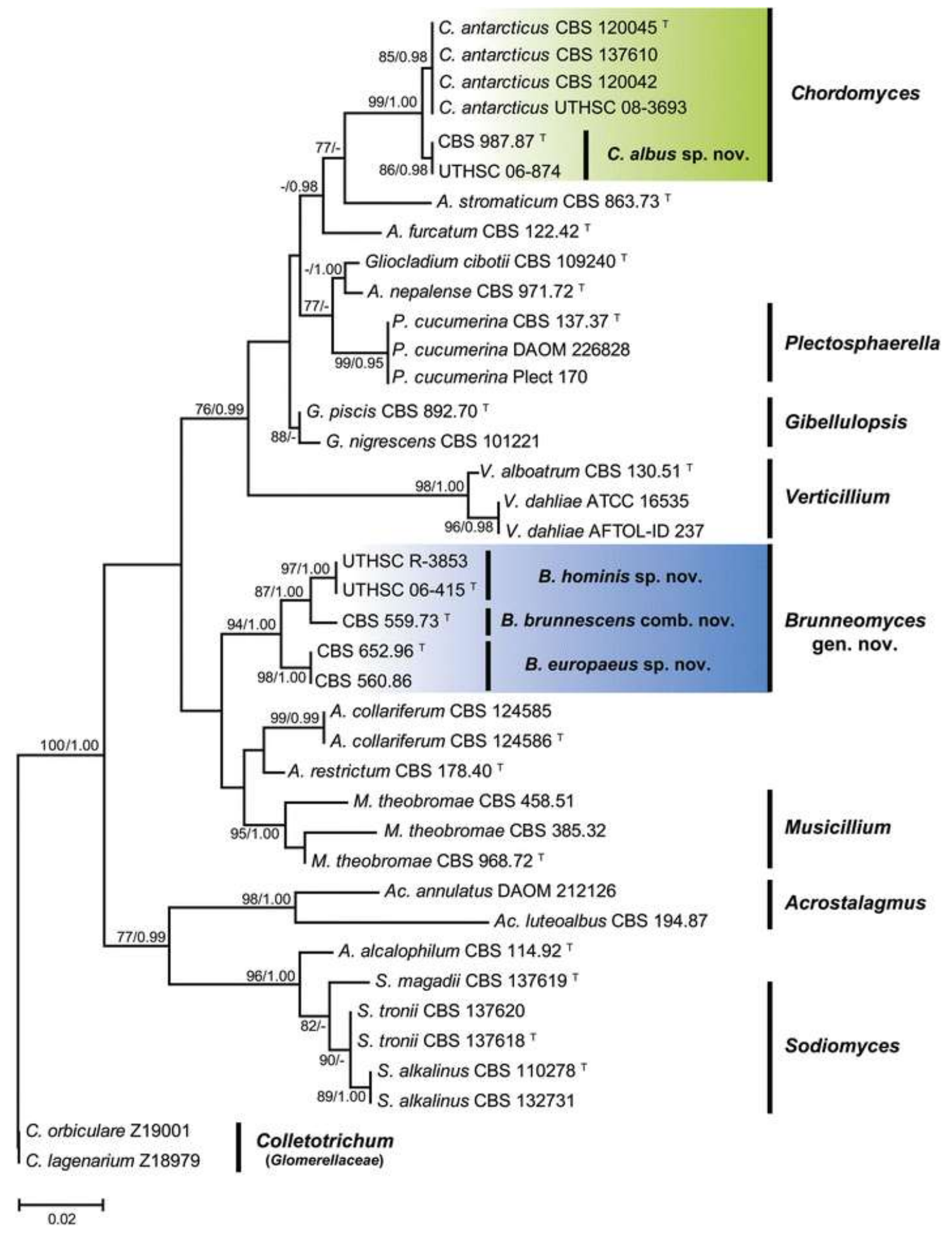

Fig. 4 Maximum composite likelihood tree based on analysis of ITS and partial LSU, RPB2 and TEF1- $\alpha$ sequences of genera of the Plectosphaerellaceae and related genera. Bootstrap support values above 70 $\%$ / Bayesian posterior probability values above 0.95 , are shown at the nodes. ${ }^{\top}$, Type strain

grouped with the ex-type strain of $C$. antarcticus (BS $=85 \%$; $\mathrm{PP}=0.98$ ), UTHSC 06-874 clustered with strain CBS 987.87 in a separated subclade (BS = $86 \%$; PP $=0.98)$. Because the last two isolates were phylogenetically distant 
from the clade of $C$. antarcticum, the new species Chordomyces albus is proposed. In the same analysis, a monophyletic group ( $\mathrm{BS}=94 \%$; $\mathrm{PP}=1.00$ ) was formed by all isolates of the group $\mathrm{R}$, two reference strains of $A$. hyalinulum formed a well-supported clade ( $B S=98 \%$; $P P=1.00)$, two clinical isolates (UTHSC R-3853 and UTHSC 06-415) clustered together with high support (BS $=97 \% ; \mathrm{PP}=1.00$ ), while the ex-type strain of $A$. brunnescens formed a single branch. This novel lineage of acremonium-like fungi within the Plectosphaerellacae is proposed as a new genus, Brunneomyces based on $A$. brunnescens, and the two new species, $B$. hominis and $B$. europaeus.

\section{Taxonomy}

Acremonium dimorphosporum Giraldo, Deanna A. Sutton \& Gené, sp. nov. [MB 811461] Fig. 5
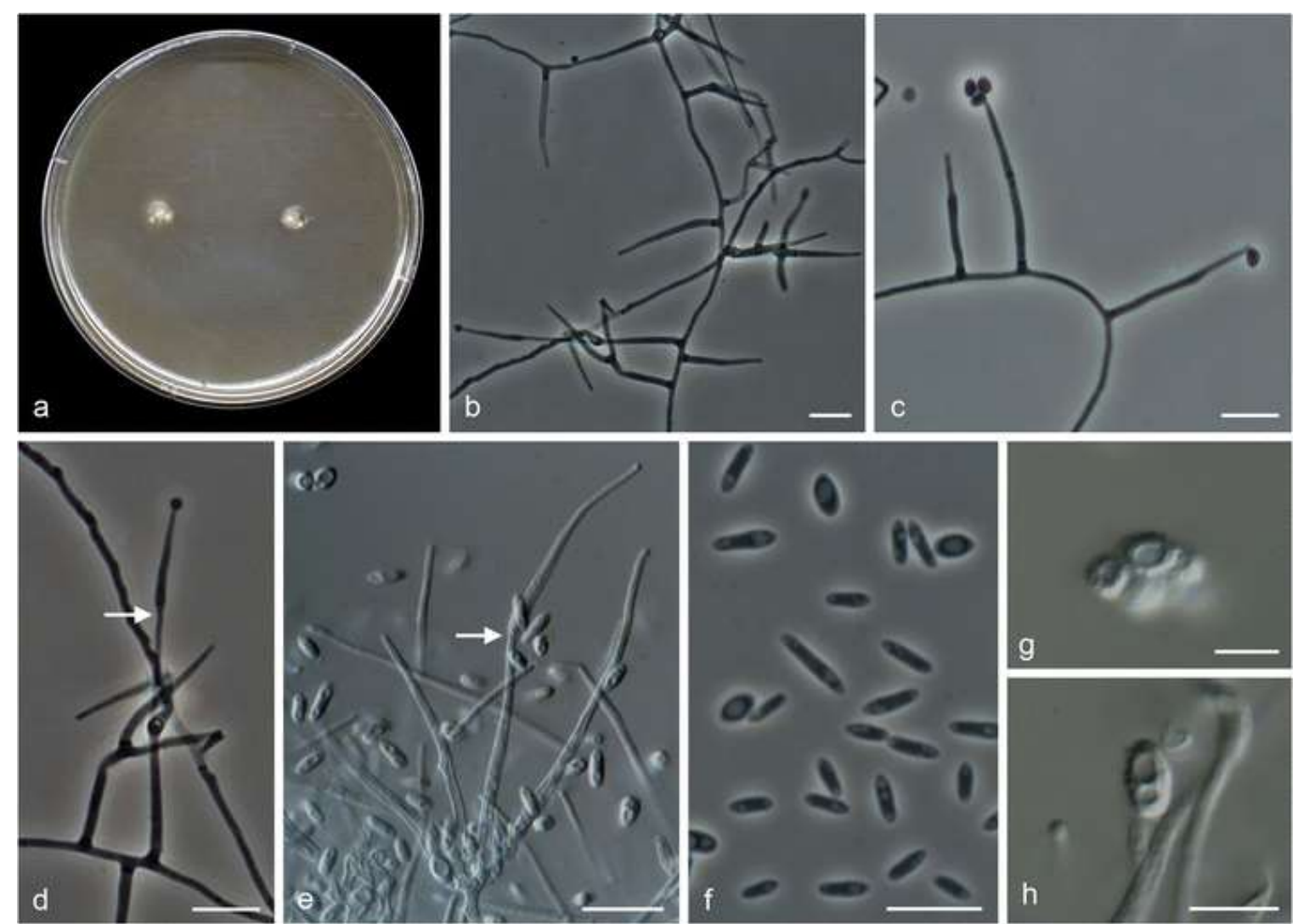

Fig. 5 Acremonium dimorphosporum UTHSC 08-3639. a Colonies on OA, after 21 days at $25^{\circ} \mathrm{C}$. b, c Simple conidiophores and conidia forming heads. d, e Phialides with percurrent proliferation (arrow). $\mathbf{f}-\mathbf{h}$ Smooth-walled, ellipsoidal (f) and thick-walled, verrucose, ovoidal conidia ( $h$ ). Scale bars: $b-f=10 \mu m, g, h$ $=5 \mu \mathrm{m}$ 
Etymology. The name refers to the dimorphic conidia produced by the species.

Colonies at $25^{\circ} \mathrm{C}$ after 14 days on $\mathrm{OA}$ reaching $10-11 \mathrm{~mm}$ diam, white (1A1) to yellowish white (4A2), flat, with scarce aerial mycelium, reverse colourless; at $25{ }^{\circ} \mathrm{C}$ after 14 days on PDA reaching $14-15 \mathrm{~mm}$ diam, pinkish white (7A2), flat, cottony, reverse orange (6A6). Mycelium consisting of hyaline, smooth- and thin-walled, 1.5-2 $\mu \mathrm{m}$ wide hyphae. Conidiophores erect, usually reduced to single phialides emerging from vegetative hyphae, occasionally basitonously branched and then bearing 2-4 phialides, straight, up to $60 \mu \mathrm{m}$ long, hyaline, smooth, with cell walls usually thicker than those of the vegetative hyphae. Phialides subulate, 17-30(45) $\mu \mathrm{m}$ long, 1-1.5 $\mu \mathrm{m}$ wide at the base, hyaline, thick- and smooth-walled, often borne on short cylindrical subtending cells; percurrently proliferating phialides are occasionally present. Conidia arranged in slimy heads, 1-celled, hyaline, of two types: i) cylindrical with more or less rounded ends, 3-7 × 1-1.5 $\mu \mathrm{m}$, thin- and smooth-walled; ii) ellipsoidal, 3-4 × 2$3 \mu \mathrm{m}$, thick- and rough-walled. Chlamydospores and sexual morph not observed.

Cardinal temperatures for growth: Optimum $20-25^{\circ} \mathrm{C}$, maximum $30^{\circ} \mathrm{C}$, minimum $15^{\circ} \mathrm{C}$.

Specimen examined. USA, Texas, from bronchoalveolar lavage fluid, 2008, D.A. Sutton (holotype CBS H-22021, dried culture on OA; cultures ex-type CBS $139050=$ FMR $10548=$ UTHSC 08-3639).

Notes: Although $A$. dimorphosporum is phylogenetically distant to $A$. borodinense, it is morphologically similar to that species in producing both ellipsoidal rough-walled and cylindrical smooth-walled conidia (Ito et al. 2000). However, A. borodinense differs from $A$. dimorphosporum by its faster growth at $25{ }^{\circ} \mathrm{C}(27-29 \mathrm{~mm}$ diam. after $10 \mathrm{~d})$ and by its ability to grow at $37^{\circ} \mathrm{C}$. Furthermore, its cylindrical conidia are slightly curved and smaller (4.5-5.5 $\mu \mathrm{m}$ long), and its ellipsoidal and rough-walled conidia are larger $(4.2-5.5 \times 3-4 \mu \mathrm{m})$ than those of $A$. dimorphosporum. 
Acremonium moniliforme Giraldo, Deanna A. Sutton \& Guarro, sp. nov. [MB 811462] Fig. 6
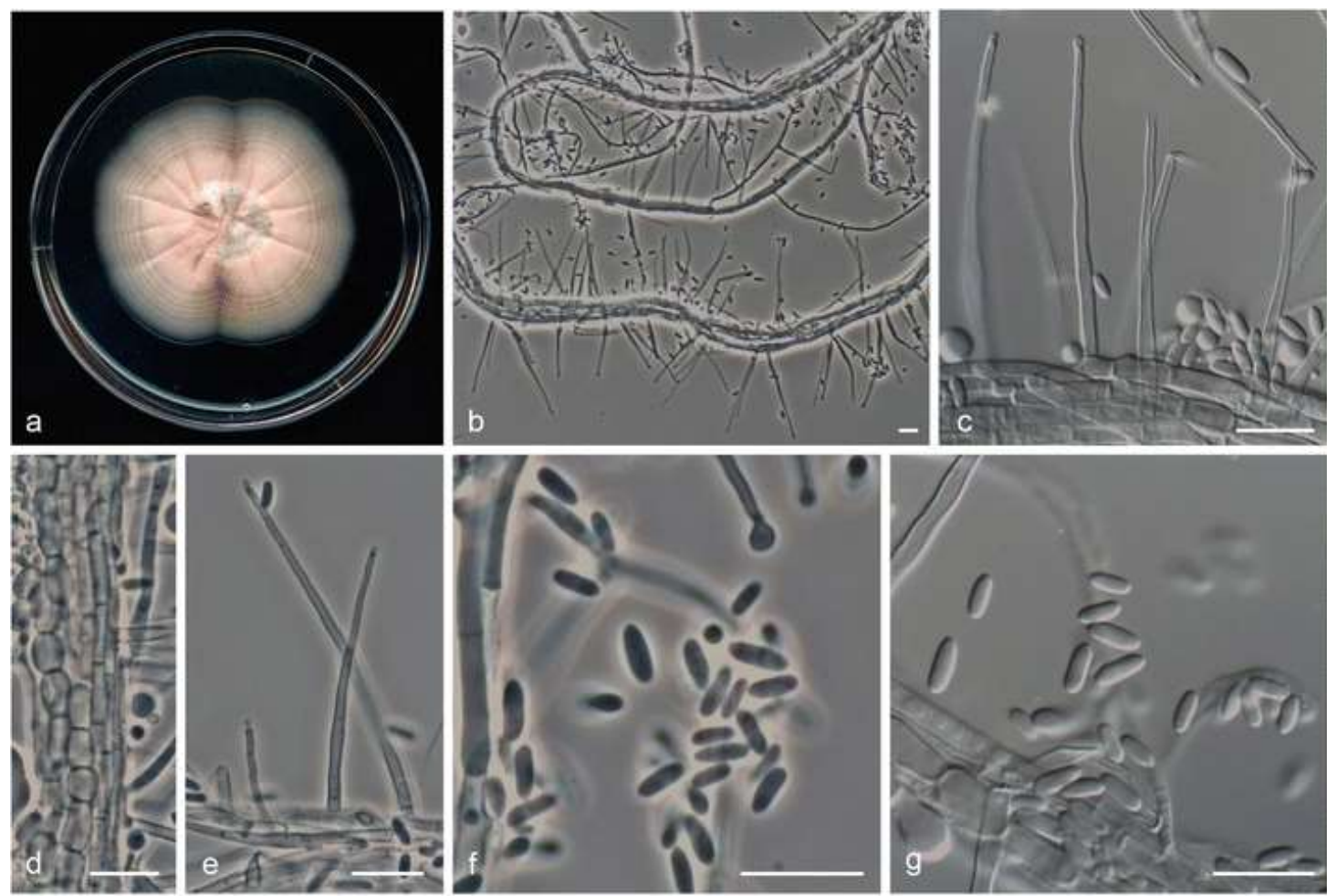

Fig. 6 Acremonium moniliforme FMR 11785. a Colonies on PDA after 14 days at $25^{\circ} \mathrm{C}$. b, c Simple conidiophores arising laterally from ropes of hyphae. d Monilifom hyphae. e Phialide with periclinal thickening at the apex. $\mathbf{f}, \mathbf{g}$ Conidia. Scale bars $=10 \mu \mathrm{m}$

Etymology. The name refers to the presence of monilifom hyphae.

Colonies at $25^{\circ} \mathrm{C}$ after 14 days on OA reaching $45-60 \mathrm{~mm}$ diam, yellowish white (4A2), flat, glabrous; reverse colourless; at $25^{\circ} \mathrm{C}$ after 14 days on PDA reaching 36-50 mm diam, pinkish white (7A2), radially folded, zonate towards the periphery, felty, greyish red (7B4); reverse salmon (6A4). Mycelium consisting of branched, septate, hyaline, smooth- and thick-walled hyphae, initially 2-2.5 $\mu \mathrm{m}$ wide, often swelling at maturity, becoming barrel-shaped, up to $7 \mu \mathrm{m}$ wide. Conidiophores reduced to conidiogenous cells, emerging laterally from hyphae. Phialides acicular with a slightly flexuose apex, 30-50 $\mu \mathrm{m}$ long, 1.5-2 $\mu \mathrm{m}$ wide at the base, with a distinct periclinal thickening, thick- and smooth-walled, hyaline. Conidia arranged in slimy heads, 1-celled, cylindrical with rounded ends, 3-5(6) × 1-2 $\mu \mathrm{m}$, hyaline, thick- and smooth-walled. Chlamydospores and sexual morph not observed.

Cardinal temperatures for growth: Optimum $25-30{ }^{\circ} \mathrm{C}$, maximum $37^{\circ} \mathrm{C}$, minimum below $4^{\circ} \mathrm{C}$. 
Specimens examined: Spain, Aragón, Huesca province, Ordesa y Monte Perdido National Park, from forest soil, 2011, coll. A. Giraldo, M. Hernández, \& J. Capilla, isol. A. Giraldo (holotype CBS H-22022, dried culture on OA; cultures ex-type CBS 139051 = FMR 11785). USA, Utah, from toe nail, 2008, D.A. Sutton (FMR 10363 = UTHSC 08-2284).

Notes: Acremonium monilifome is phylogenetically distant from the species of the Emericellopsis clade. It can be morphologically differentiated from other Acremonium species by the production of abundant moniliform hyphae. Acremonium fuci occasionally produces small rounded hyphal swellings, similar to the moniliform hyphae of $A$. moniliforme. However, both species can be distinguished by the conidial shape, which is obovoid or broadly ellipsoidal in the former, and cylindrical in the latter. Additionally, the maximum temperature for growth in A. fuci is $33^{\circ} \mathrm{C}$ (Zuccaro et al. 2004), while in A. moniliforme it is $37^{\circ} \mathrm{C}$.

\section{Brunneomyces Giraldo, Gené \& Guarro, gen. nov. [MB 811471]}

Type species. Brunneomyces brunnescens (W. Gams) Giraldo, Gené \& Guarro

Etymology. The name refers to brownish pigmented hyphae formed by the type species of this genus.

Mycelium consisting of branched, septate, hyaline and thin-walled hyphae, often becoming dark brown, verrucose and thick-walled with age. Conidiophores erect, unbranched or poorly branched, often proliferating sympodially, showing conidiogenous cells as short lateral and cylindrical projections. Conidiogenous cells enteroblastic, mono- and polyphialidic, hyaline, terminal, lateral or intercalary (adelophialides), subulate, lageniform or cylindrical, usually with short cylindrical collarettes, often subhyaline or pale brown, and with a distinct periclinal thickening at the conidiogenous locus. Conidia arranged in chains, 1-celled, pyriform or ellipsoidal, hyaline or brown. Sexual morph unknown. 
Brunneomyces brunnescens (W. Gams) Giraldo, Gené \& Guarro, comb. nov. [MB 811472] Fig. 7

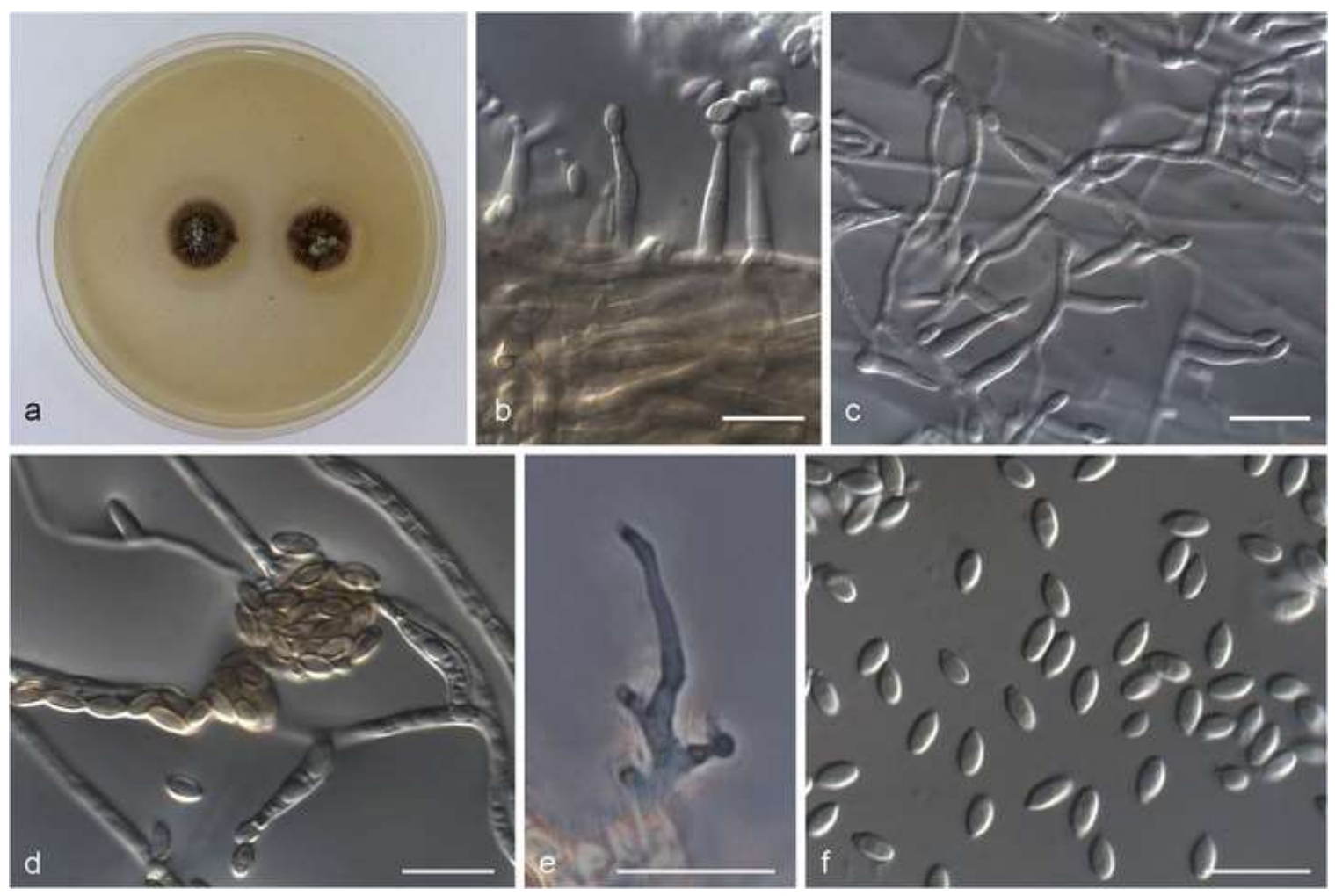

Fig. 7 Brunneomyces brunnescens CBS 559.73. a Colonies on OA after 14 days at $25^{\circ} \mathrm{C}$. b Brown pigmented hyphae. c Discrete phialides. d Phialides with slightly pigmented collarettes and conidial chains collapsing in slimy heads. e Sympodial conidiophore. $\mathbf{f}$ Conidia. Scale bars $=10 \mu \mathrm{m}$

Basionym. Acremonium brunnescens W. Gams, Trans. Br. Mycol. Soc., 64: 398. 1975.

Specimen examined. Sri Lanka, Hakgala Bot. Gardens, from dead stem of Dendrocalamus giganteus, Jan. 1973, W. Gams (holotype CBS H-6641, dried plant material; cultures ex-type CBS $559.73=$ ATCC $32180=$ IMI 185378).

Notes: Although the three species of Brunneomyces show a similar conidiogenous apparatus to that of the genus Acremonium, they can be distinguished by the presence of sympodial conidiophores and dark brown, verrucose, thick-walled hyphae. The combination of these morphological features are usually absent in the species of Acremonium and other genera of plectosphaerellaceous fungi. In addition, Brunneomyces is the only genus of the Plectosphaerellaceae with conidial chains.

A detailed description of B. brunnescens was given in Gams (1975). Most relevant features of the ex-type strain of this species (CBS 559.73) studied here 
were: slow growing colonies (6-8 $\mathrm{mm}$ and $21-22 \mathrm{~mm}$ diam. after $14 \mathrm{~d}$ on PDA and $O A$, respectively) with a mushroom-like odour, pigmented verrucose hyphae and dark brown conidia appearing after 21 days, phialides with short cylindrical and slightly pigmented collarettes, adelophialides of 6-10 × 1.5-2.5 $\mu \mathrm{m}$, and conidial chains often collapsing soon in slimy heads. In addition, this fungus was unable to grow above $32^{\circ} \mathrm{C}$.

Brunneomyces hominis Giraldo, Deanna A. Sutton \& Gené, sp. nov. [MB811473] Fig. 8
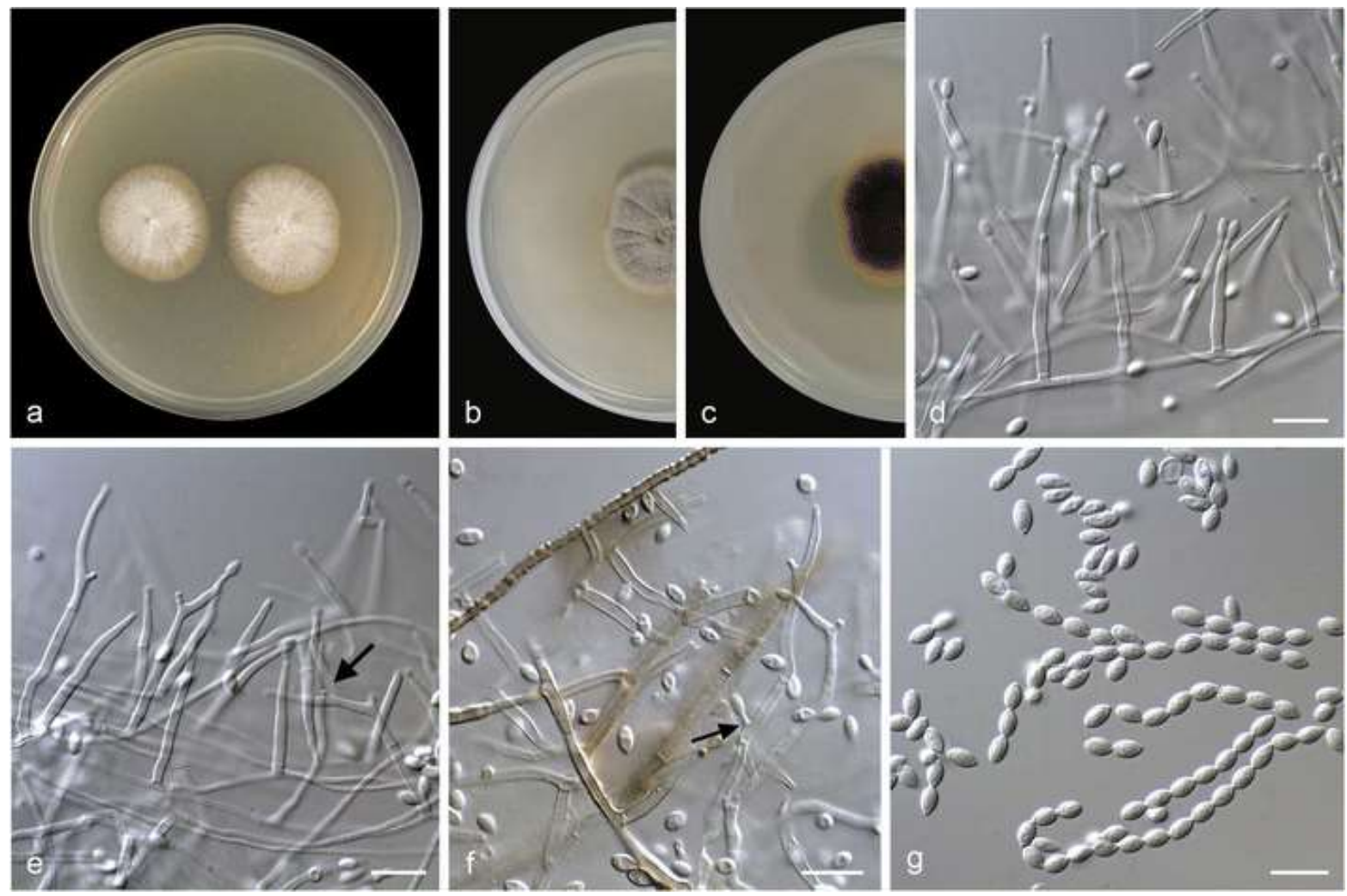

Fig. 8 Brunneomyces hominis a-c, f, g UTHSC 06-415; d, e UTHSC R-3853. a Colonies on OA after 14 days at $25{ }^{\circ} \mathrm{C}$. b, c Colonies on PDA after 21 days at $25^{\circ} \mathrm{C}$ obverse and reverse, respectively. d Unbranched conidiophores. e Unbranched conidiophores with terminal polyphialides and a sympodial conidiophore (arrow). f Pigmented verrucose hyphae and intercalary phialide (arrow). g Conidia. Scale bars $=10 \mu \mathrm{m}$

Etymology: The name refers to the isolation source of the type strain, human clinical samples.

Colonies at $25{ }^{\circ} \mathrm{C}$ after 14 days on $\mathrm{OA}$ reaching $26-28 \mathrm{~mm}$ diam, orange white (6A2), flat, dusty; reverse colourless; at $25^{\circ} \mathrm{C}$ after 14 days on PDA reaching $17-18 \mathrm{~mm}$ diam, grey $(5 \mathrm{~F} 1)$ at the centre, yellowish white $(4 \mathrm{~A} 2)$ at the 
periphery, crateriform and radially folded, felty; reverse grey (5F1). Strong mushroom-like (moist soil) odour. Mycelium consisting of septate, hyaline, smooth- and thin-walled hyphae, 1.5-2 $\mu \mathrm{m}$ wide at the beginning, becoming dark brown, verrucose and thick-walled, up to $3 \mu \mathrm{m}$ wide with age. Conidiophores erect, mostly unbranched, occasionally with a few branches and proliferating sympodially, straight or slightly bent, up to $35 \mu \mathrm{m}$ long, hyaline, smooth-walled. Phialides subulate, 12-20(30) $\mu \mathrm{m}$ long, 1.5-2 $\mu \mathrm{m}$ wide at the base, hyaline at first, dark brown in old cultures, thick- and smooth-walled, with conspicuous periclinal thickening and cylindrical collarettes; adelophialides sometimes present, up to $10 \mu \mathrm{m}$ long; polyphialides with up to two conidiogenous loci commonly present. Conidia arranged in long dry chains, 1celled, pyrifom or ellipsoidal, 4-5(6) × 2-2.5 $\mu \mathrm{m}$, with truncate base, subhyaline, thin- and smooth-walled. Chlamydospores and sexual morph not observed.

Cardinal temperatures for growth: Optimum $25-30{ }^{\circ} \mathrm{C}$, maximum $35^{\circ} \mathrm{C}$, minimum below $4^{\circ} \mathrm{C}$.

Specimens examined. USA, Minnesota, from human sputum, 2006, D.A. Sutton (holotype CBS H-22023, dried culture on OA; cultures ex-type CBS $139053=$ FMR $10429=$ UTHSC 06-415). California, from human sputum, D.A. Sutton $($ CBS $139054=$ FMR $10437=$ UTHSC R-3853).

Notes: The colourless colony reverse on OA distinguishes $B$. hominis from the dark grey reverse in $B$. brunnescens. Brunneomyces hominis produces long, dry conidial chains, while in $B$. europaeus and $B$. brunnescens chains tend to collapse in slimy heads. It is the only Brunneomyces species able to grow at $35^{\circ} \mathrm{C}$. 
Brunneomyces europaeus Giraldo, Gené \& Guarro, sp. nov. [MB811474] Fig. 9
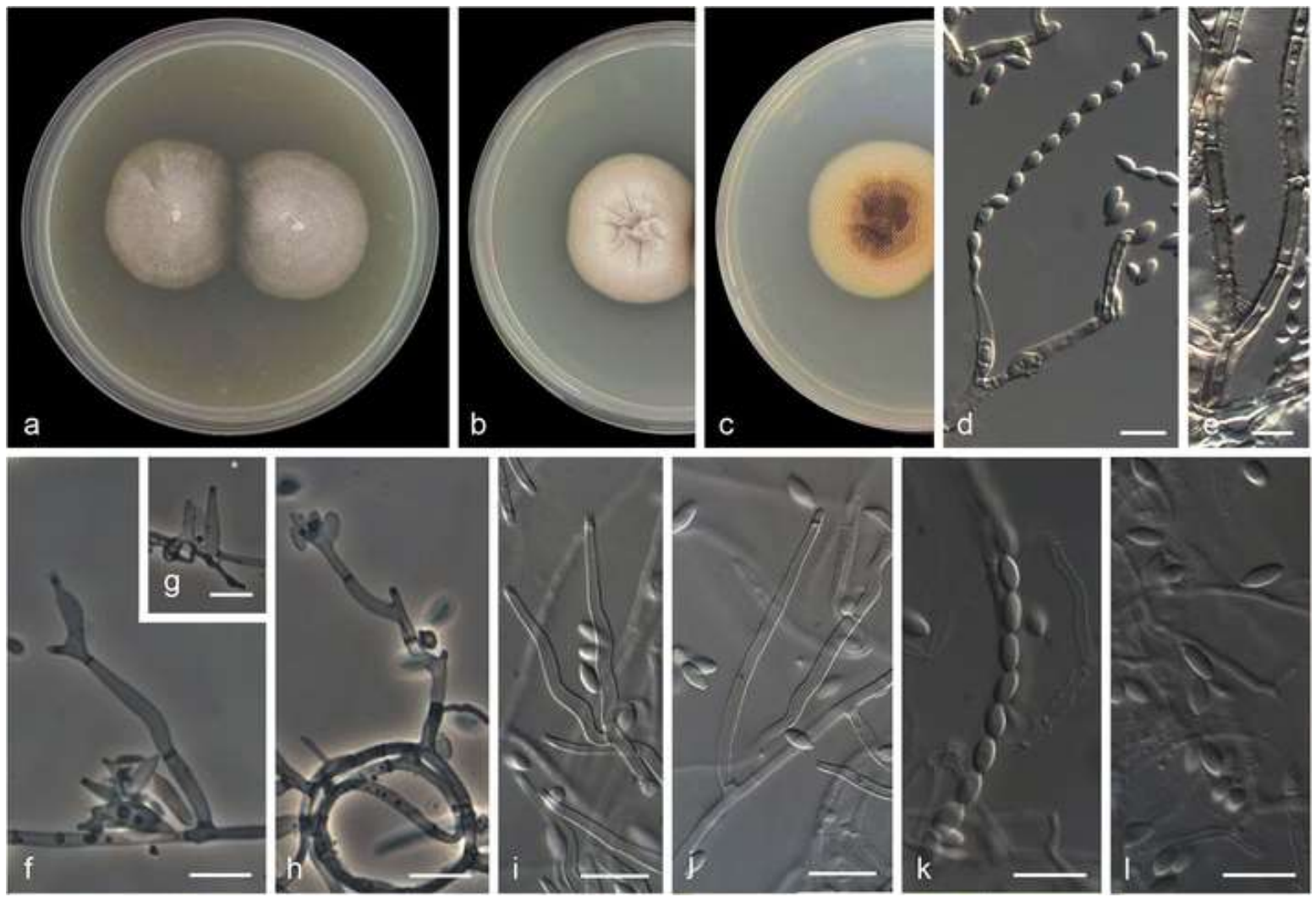

Fig. 9 Brunneomyces europaeus a-c, f-h, k, I CBS 560.86; d, e, i, j CBS 652.96. a Colonies on OA after 14 days at $25^{\circ} \mathrm{C}$. b, c Colonies on PDA after 14 days at $25^{\circ} \mathrm{C}$ obverse and reverse, respectively. d. Phialide producing a long conidial chain. e Pigmented verrucose hyphae. f Polyphialide. $\mathbf{g}$ Adelophialide. $\mathbf{h}$ Sympodial conidiophore. i, j Phialides with short cylindrical collarettes. $\mathbf{k}$, I Conidia. Scale bars $=10 \mu \mathrm{m}$

Etymology: The name refers to the geographic origin of the isolates, Europe.

Colonies at $25^{\circ} \mathrm{C}$ after 14 days on $\mathrm{OA}$ reaching $31-50 \mathrm{~mm}$ diam, yellowish white (4A2), flat, dusty; reverse colourless; at $25{ }^{\circ} \mathrm{C}$ after 14 days on PDA reaching $25-36 \mathrm{~mm}$ diam, greyish brown (6E2) at the centre, white (1A1) to orange-white (6A2) towards the periphery, radially folded, felty; reverse brown (6E2). Slight mushroom-like (moist soil) odour. Mycelium consisting of septate, hyaline, smooth- and thin-walled hyphae, 2-2.5 $\mu \mathrm{m}$ wide, becoming brownish, verrucose and thick-walled with age. Conidiophores erect, usually unbranched, some proliferating sympodially, up to $45 \mu \mathrm{m}$ long, straight or slightly bent, hyaline to subhyaline, smooth-walled. Phialides subulate or somewhat cylindrical, 15-35(40) $\mu \mathrm{m}$ long, 2-3 $\mu \mathrm{m}$ wide at the base, hyaline, thick- and smooth-walled, with a distinct periclinal thickening at the conidiogenous locus and short cylindrical collarettes; adelophialides sometimes present, up to $15 \mu \mathrm{m}$ 
long; polyphialides with up to three conidiogenous loci commonly present. Conidia forming chains that soon collapse in slimy heads, 1-celled, ovoidal to ellipsoidal, 5-6(7) $\times 2-3 \mu \mathrm{m}$, with a distinctly truncate base, subhyaline, thinand smooth-walled. Chlamydospores and sexual morph not observed.

Cardinal temperatures for growth: Optimum $20-25{ }^{\circ} \mathrm{C}$, maximum $32{ }^{\circ} \mathrm{C}$, minimum below $4^{\circ} \mathrm{C}$.

Specimens examined. Spain, Riumar, from sediments of Ebro River, 1991, coll. K. Ulfig, isol. J. Gené (holotype CBS H-22024, dried culture on OA; cultures ex-type CBS 652.96 = FMR 3962). France, Provence, from leaf of Bambusa sp., Dec. 1986, O. Petrini (CBS 560.86 = FMR 3406).

Notes: The two isolates of $B$. europaeus were previously identified wrongly as $A$. hyalinulum because they form brownish pigmented and verrucose hyphae, sympodially proliferating conidiophores and intercalary phialides that all are not mentioned in the protologue of $A$. hyalinulum (Gams 1971). The latter was described with hyaline smooth-walled hyphae, and lacking adelophialides. However, there is no ex-type strain of $A$. hyalinulum for a reliable comparison and, according to different studies, it seems to be a polyphyletic species (Perdomo et al. 2011; Summerbell et al. 2011).

\section{Chordomyces Bilanenko, M.L. Georgieva \& Grum-Grzhimaylo [Emmend]}

Type species. Chordomyces antarcticus Bilanenko ML, Georgieva \& GrumGrzhimaylo

Modified from original description (Grum-Grzhimaylo et al. 2016): Colonies white, tufted, restricted to moderate fast growing. Mycelium superficial or immersed, consisting of septate, hyaline, thin- and smooth-walled hyphae. Conidiophores phalacrogenous, plectonematogenous or synnematogenous, unbranched or branched, or consisting of single phialides. Synnemata when present, hyaline, without a differential sterile base, sometimes branched, appearing fimbriate due to radiating phialides. Conidiogenous cells mono- or polyphialidic, tapering to the apex, hyaline, often proliferating sympodially. Conidia arranged in slimy heads, 1(-2)-celled, subglobose, limoniform, ellipsoidal to cylindrical, rounded at the apex, sometimes with protuberant hilum, hyaline and smooth-walled. Sexual morph unknown. 
Chordomyces albus Giraldo, Deanna A. Sutton \& Guarro, sp. nov. [MB 811476] Fig. 10
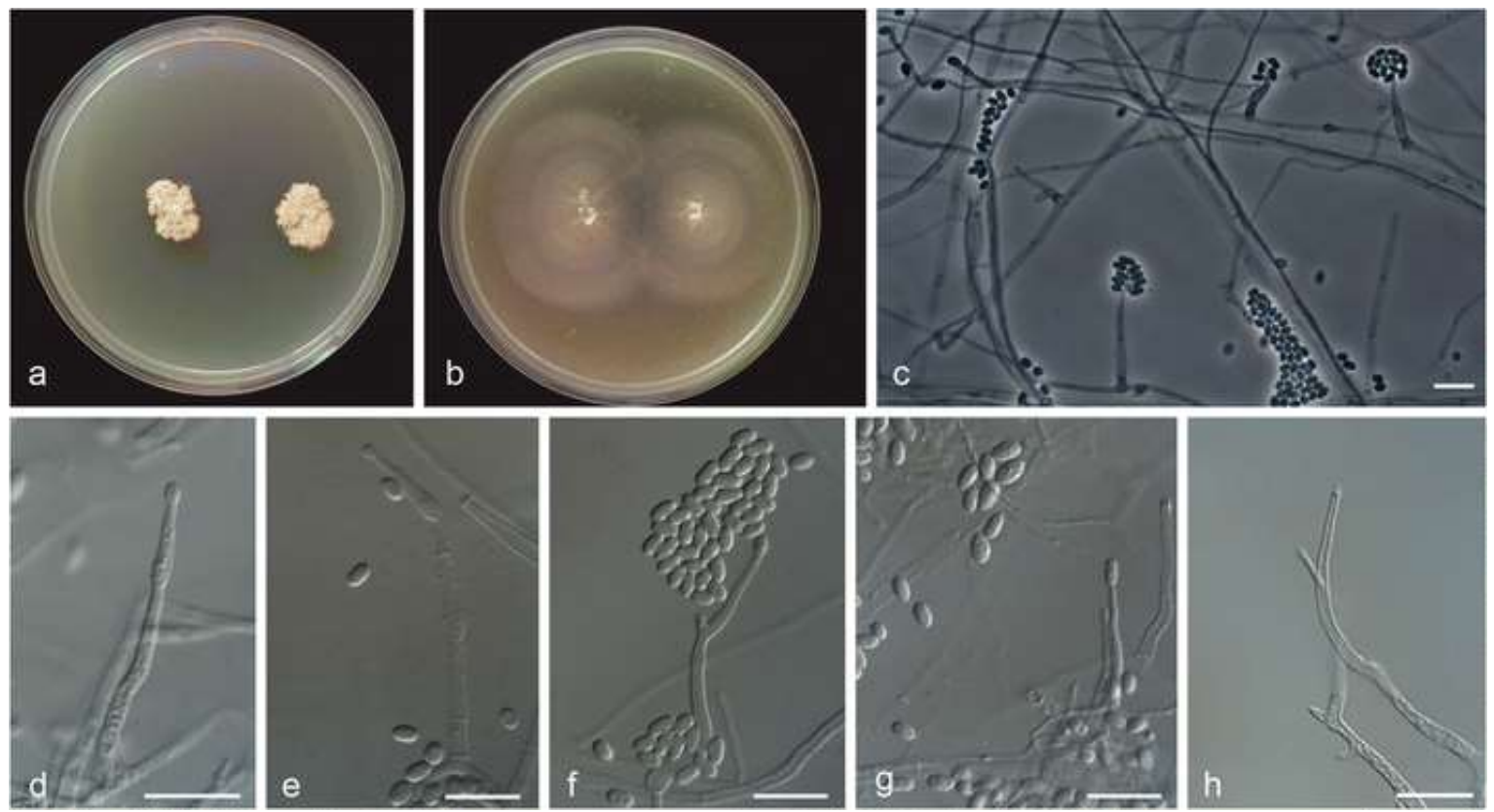

Fig. 10 Chordomyces albus CBS 987.87. a, b Colonies on PDA and OA, respectively, after 14 days at 25 ${ }^{\circ} \mathrm{C}$. c Unbranched conidiophores. d, e Phialides with percurrent proliferations. $\mathbf{f}, \mathbf{g}, \mathbf{h}$ Phialides with cylindrical collarettes and conidia. Scale bars $=10 \mu \mathrm{m}$

Etymology: The name refers to light coloured colonies formed by the species.

Colonies at $25{ }^{\circ} \mathrm{C}$ after 14 days on OA reaching $40-41 \mathrm{~mm}$ diam, yellowish white (4A2), flat, dusty; reverse colourless; at $25{ }^{\circ} \mathrm{C}$ after 14 days on PDA reaching 10-11 mm diam, pale yellow (4A3), raised, cerebriform; reverse colourless. Mycelium consisting of septate, hyaline, smooth- and thin-walled hyphae, 1.5-2 $\mu \mathrm{m}$ wide. Conidiophores erect, unbranched, consisting of one or two cells, or with branches from near the middle bearing 3-4 phialides, up to 30 $\mu \mathrm{m}$ long, straight or slightly curved, hyaline to subhyaline, smooth-walled. Synnemata absent. Phialides cylindrical or subulate, 12-22 $\mu \mathrm{m}$ long, 2-2.5 $\mu \mathrm{m}$ wide at the base, with a distinct periclinal thickening at the conidiogenous locus and cylindrical collarettes, occasionally with a percurrent proliferation, hyaline, thick- and smooth-walled, sometimes with a second conidiogenous locus emerging laterally as an up to $5 \mu \mathrm{m}$ long cylindrical projection near the basal septum. Conidia in slimy heads, 1-celled, ellipsoidal to near cylindrical, 3-4 × 2$2.5 \mu \mathrm{m}$, subhyaline, thick- and smooth-walled. Chlamydospores and sexual morph not observed. 
Cardinal temperature for growth: Optimum $20-25{ }^{\circ} \mathrm{C}$, maximum $32{ }^{\circ} \mathrm{C}$, minimum below $4^{\circ} \mathrm{C}$.

Specimens examined. Luxembourg, Hautecharage, on Hypogymnia physodes, Dec. 1987, coll. G. Marson, isol. W. Gams (holotype CBS H-8083, dried plant material; cultures ex-type CBS $987.87=$ FMR 10886). USA, Hawaii, from human sputum, 2006, D.A. Sutton (FMR 10433 = UTHSC 06-874).

Notes: The genus Chordomyces was recently proposed by Grum-Grzhimaylo et al. (2016) to accommodate $C$. antarcticus. Most isolates of $C$. antarcticus but CBS 987.87 derived from soda soil and were alkalitolerant. Strain CBS 987.87 was previously wrongly identified as $A$. antarcticum; however, it differs from the protologue of that species in the presence of schizophialides with conspicuous cylindrical collarettes and percurrent conidiophores (Spegazzini 1910; Hawksworth 1979). Furthermore, its DNA sequences differ significantly from $C$. antarcticus strains in Grum-Grzhimaylo et al. (2016). In the present study, CBS 987.87 and the clinical isolate UTHSC $06-874$ have been found to be morphologically and genetically similar and, since they formed a novel lineage into the Chordomyces clade, they are proposed as a second species in the genus. Chordomyces albus morphologically differs from $C$. antarcticus in the absence of synnemata in culture, in having a faster growth on $O A$ at $25^{\circ} \mathrm{C}(40-$ $41 \mathrm{~mm}$ vs. 22-28 mm in 14 days), shorter phialides (12-22 um long vs. 28-30 $\mu \mathrm{m}$ long) and conidia without a protuberant hilum (Grum-Grzhimaylo et al. 2016).

\section{Discussion}

Two bionectriaceus species are newly described. Acremonium dimorphosporum is phylogenetically related to species of the fusidioides clade (Summerbell et al. 2011; Giraldo et al. 2014). Conidial dimorphism seen also in other species of the fusidioides clade supports this phylogenetic inference, although no conidial chains but slimy masses were observed in A. dimorphosporum (Gams 1971; Ito et al. 2000; Giraldo et al. 2012, 2014). Acremonium moniliforme is phylogenetically closely related to species of the Emericellopsis clade, a welldefined monophyletic group within the Bionectriaceae accomodating also the type species of the synnematous genus Stilbella, S. fimetaria (Seifert 1985), the 
type species of Stanjemonium, S. grisellum (Gams et al. 1998), and Acremonium species, such as $A$. tubakii, $A$. fuci, $A$. exuviarum and $A$. salmoneum (Sigler et al. 2004; Zuccaro et al. 2004; Summerbell et al. 2011; Grum-Grzhimaylo et al. 2013b). Members of this clade are commonly isolated from soil, dung, marine water, and occasionally from animal lesions (Sigler et al. 2004; de Hoog et al. 2015; Grum-Grzhimaylo et al. 2013b). The origin of the two strains of $A$. moniliforme, i.e. human nail from USA and soil from Spain, suggests that it is a widespread species as other species of this group.

Phylogenetic analyses of concatenated sequences from four loci support the monophyly of Brunneomyces and places the genus in the Plectosphaerellaceae. This family was introduced by Gams, Summerbell and Zare (Zare et al. 2007) and recently assigned to the Glomerellales (Maharachchikumbura et al. 2016). Currently, it comprises nine genera, i.e. Acrostalagmus, Gibellulopsis, Lectera, Musicillium, Plectosphaerella, Stachylidium, Verticillium sensu stricto and the recently described Chordomyces and Sodiomyces (Zare et al. 2007; Inderbitzin et al. 2011; Réblová et al. 2011; Cannon et al. 2012; Grum-Grzhimaylo et al. 2013a, 2016). In addition, Gliocladium cibotii and some Acremonium species, including A. collariferum, $A$. furcatum, $A$. nepalense, $A$. restrictum and $A$. stromaticum, belong to this family (Zare et al. 2007; Weisenborn et al. 2010; Carlucci et al. 2012). Morphologically, species of Acrostalagmus, Gibellulopsis, Musicillium, Stachylidium and Verticillium are mainly characterized by hyaline or light brown verticillate conidiophores (Hughes 1951; Zare et al. 2007; Inderbitzin et al. 2011; Réblová et al. 2011); Lectera produces brightly coloured sporodochia and brown setae (Cannon et al. 2012); the asexual morphs of Sodiomyces and Plectosphaerella have verticillate or penicillate conidiophores and septate conidia (Carlucci et al. 2012; Grum-Grzhimaylo et al. 2013a, 2016); Chordomyces, G. cibotii and above-mentioned Acremonium species form mostly cylindrical or ellipsoidal conidia arranged in slimy heads (Gams 1971, 1975; Zare et al. 2007; Weisenborn et al. 2010; Grum-Grzhimaylo et al. 2016). By contrast, the species of Brunneomyces are characterized by the production of sympodially proliferating conidiophores, ovoidal or ellipsoidal conidia arranged in chains and dark verruculose hyphae. Subglobose to oval conidia, conspicuous funnelshaped collarette and olive-brown chlamydospores distinguishes $A$. collariferum 
from Brunneomyces although it also forms verruculose hyphae (Weisenborn et al. 2010). In addition, A. collariferum did not produce conidial chains in any of the culture media tested here.

The genus Phaeoacremonium (Togniniaceae, Diaporthales) resembles Brunneomyces in having verruculose, pale brown hyphae and polyphialides. However, it is phylogenetically distant and its species produce conidia in slimy heads (Crous et al. 1996; Mostert et al. 2006).

Our phylogenetic analysis supports the monophyly of Chordomyces and the existence of a new species, $C$. albus. Based on morphological features of $C$. antarcticus the monotypic genus was restricted to fungi with cylindrical to ellipsoidal conidia (Grum-Grzhimaylo et al. 2016). However, UTHSC 08-3693 produced subglobose to limoniform conidia in all media tested. Therefore, the concept of Chordomyces is emended here accordingly.

The habitats of the members of Plectosphaerellaceae are quite diverse. Verticillium, Musicillium, Plectosphaerella and Lectera are well-known pathogens of different kinds of plants, including legumes, banana, cucurbits, potatoes, and others (Cannon et al. 2012; Carlucci et al. 2012; Masudi and Bonjar 2012; Hyde et al. 2014). Acrostalagmus luteoalbus has been reported also as a fungicolous species (Gams et al. 2004); Gibellulopsis nigrescens and most of the plectosphaerellaceous Acremonium species are soil-borne saprobes (Gams 1975; Domsch et al. 2007; Zare et al. 2007). Gibellulopsis piscis and Plectosphaerella oratosquillae have occasionally been reported as pathogens of fish and shrimp, respectively (Batista and da Silva 1959; Duc et al. 2009), and some species such as Stachylidium bicolor, Acremonium alcalophilum, Chordomyces and Sodiomyces species possess alkaliphilic or alkalitolerant abilities (Grum-Grzhimaylo et al. 2013a,b; 2016). The species of Brunneomyces and Chordomyces studied here seem to be saprotrophic; they are typically recovered from plant debris. Although, the isolates included in $B$. hominis, and some of $C$. albus and $C$. antarcticus are from human specimens (human nails and sputum), their human-related pathogenic role is unknown.

Acknowledgements The authors would like to thank Prof. Dr, G.S. de Hoog and the curator of the culture collection CBS-KNAW Fungal Biodiversity Centre for providing valuable strains from their collection. This study was supported by 
the Spanish Ministerio de Economía y Competitividad, grant CGL2013-43789$P$.

\section{References}

Alfaro-García A, Armengol J, Bruton BD, Gams W et al (1996) The taxonomic position of the causal agent of Acremonium collapse of muskmelon. Mycologia 88:804-808

Batista A, Silva da H (1959) Uma nova doença fungica de peixe ornamental. Anais Soc Biol Pernambuco 16:153-159

Cannon P, Buddie AG, Neergaard de E, Lübeck M, Askar MM (2012) Lectera, a new genus of the Plectosphaerellaceae for the legume pathogen Volutella colletotrichoides. MycoKeys 3:23-36

Carlucci A, Raimondo ML, Santos J, Phillips AJL (2012) Plectosphaerella species associated with root and collar rots of horticultural crops in southern Italy. Persoonia 28:34-48

Castlebury LA, Rossman AY, Sung GH, Hyten AS, Spatafora JW (2004) Multigene phylogeny reveals new lineage for Stachybotrys chartarum, the indoor air fungus. Mycol Res 108:864-872

Chaverri P, Salgado C, Hirooka Y, Rossman AY, Samuels GJ (2011) Delimitation of Neonectria and Cylindrocarpon (Nectriaceae, Hypocreales, Ascomycota) and related genera with Cylindrocarpon-like anamorphs. Stud Mycol 68:57-78

Crous PW, Gams W, Stalpers JA, Robert V, Stegehuis G (2004) MycoBank: an online initiative to launch mycology into the 21st century. Stud Mycol 50:19-22 
Crous PW, Gams W, Wingfield MJ, van Wyk, PS (1996) Phaeoacremonium gen. nov. associated with wilt and decline diseases of woody hosts and human infections. Mycologia 88:786-796

Crous PW, Wingfield MJ, Le Roux JJ, Richardson DM et al (2015) Fungal Planet description sheets. Persoonia 35:264-327

De Hoog GS, Guarro J, Gené J, Figueras MJ (2015) Atlas of clinical fungi. USB version 4.1. CBS-KNAW Fungal Biodiversity Centre, Utrecht

Domsch KH, Gams W, Anderson TH (2007) Compendium of soil fungi, 2nd edn. IHW Verlag, Eching

Duc PM, Hatai K, Kurata O, Tensha K et al (2009) Fungal infection of mantis shrimp (Oratosquilla oratoria) caused by two anamorphic fungi found in Japan. Mycopathologia 167:229-247

Edgar RC (2004) MUSCLE: multiple sequence alignment with high accuracy and high throughput. Nucleic Acids Res 32:1792-1797

Gams W (1971) Cephalosporium-artige Schimmelpilze (Hyphomycetes). Gustav Fischer Verlag, Stuttgart

Gams W (1975) Cephalosporium-like hyphomycetes: some tropical species. Trans Br Mycol Soc 64:389-404

Gams W, Diederich P, Põldmaa K (2004) Fungicolous fungi. Chapter 17. In: Müller G, Bills GF, Foster MS (eds) Measuring and monitoring biological diversity: standard methods for fungi. Academic Press, New York

Gams W, O'Donnell K, Schroers H-J, Christensen M (1998) Generic classification of some more hyphomycetes with solitary conidia borne on phialides. Can J Bot 76:1570-1583 
Giraldo A, Gené J, Cano J, Hoog S de et al (2014) Acremonium with catenate elongate conidia: phylogeny of Acremonium fusidioides and related species. Mycologia 106:328-338

Giraldo A, Gené J, Cano J, Hoog S de, Guarro J (2012) Two new species of Acremonium from Spanish soils. Mycologia 104:1456-1465

Giraldo A, Gené J, Sutton DA, Madrid H et al (2015) Phylogeny of Sarocladium (Hypocreales). Persoonia 34:10-24.

Glass NL, Donaldson GC (1995) Development of primer sets designed for use with the PCR to amplify conserved genes from filamentous Ascomycetes. Appl Environ Microb 61:1323-1330

Glenn A, Bacon CW, Price R, Hanlin RT (1996) Molecular phylogeny of Acremonium and its taxonomic implications. Mycologia 88:369-383

Gräfenhan T, Schroers HJ, Nirenberg HI, Seifert KA (2011) An overview of the taxonomy, phylogeny, and typification of nectriaceous fungi in Cosmospora, Acremonium, Fusarium, Stilbella, and Volutella. Stud Mycol 68:79-113

Grum-Grzhimaylo AA, Debets AJM, Diepeningen AD van, Georgieva ML, Bilanenko EN (2013a) Sodiomyces alkalinus, a new holomorphic alkaliphilic ascomycete within the Plectosphaerellaceae. Persoonia 31:147-158

Grum-Grzhimaylo AA, Georgieva ML, Bondarenko SA, Debets AJM, Bilanenko EN (2016) On the diversity of fungi from soda soils. Fungal Divers 76:27-74

Grum-Grzhimaylo AA, Georgieva ML, Debets AJM, Bilanenko EN (2013b) Are alkalitolerant fungi of the Emericellopsis lineage (Bionectriaceae) of marine origin? IMA Fungus 4:381-443

Guarro J (2012) Taxonomía y biología de los hongos causantes de infección en humanos. Enferm Infec Micr Cl 30:33-39. 
Gueidan C, Roux C, Lutzoni F (2007) Using multigene phylogeny analysis to assess generic delineation and character evolution in Verrucariaceae (Verrucariales, Ascomycota). Mycol Res 111:1145-1168

Hawksworth, DL (1979) The lichenicolous Hyphomycetes. Bull Br Mus nat Hist Bot 6:183-300.

Hughes SJ (1951) Stachylidium, Gonytrichum, Mesobotrys, Chaetopsis and Chaetopsella. Trans Br Mycol Soc 34:551-559.

Hujslová M, Kubátová A, Chudíčková M, Kolarik M (2009) Diversity of fungal communities in saline and acidic soils in the Soos National Natural Reserve, Czech Republic. Mycol Prog 9:1-15

Hyde KD, Nilsson RH, Alias SA, Ariyawansa HA et al (2014) One stop shop: backbones trees for important phytopathogenic genera: I. Fungal Divers 64:21125

Inderbitzin P, Bostock RM, Davis RM, Usami T et al (2011) Phylogenetics and taxonomy of the fungal vascular wilt pathogen Verticillium, with the descriptions of five new species. PLoS ONE 6:e28341

Irinyi L, Serena C, Garcia-Hermoso D, Arabatzis M et al (2015) International Society of Human and Animal Mycology (ISHAM)-ITS reference DNA barcoding database-the quality controlled standard tool for routine identification of human and animal pathogenic fungi. Med Mycol:313-337

Ito T, Okane I, Nakagiri A, Gams W (2000) Two species of Acremonium section Acremonium: $A$. borodinense sp. nov. and $A$. cavaraeanum rediscovered. Mycol Res 104:77-80.

Kornerup A, Wanscher JH (1978) Methuen handbook of colour. 3rd ed. Eyre Methuen, London 
Lehr NA, Meffert A, Antelo L, Sterner O et al (2006) Antiamoebins, myrocin B and the basis of antifungal antibiosis in the coprophilous fungus Stilbella erythrocephala (syn. S. fimetaria). FEMS Microbiol Ecol 55:105-112

Lin H-J, Chien C-Y, Huang J-W (2004) Pathogenicity and host range of Acremonium lactucae sp. nov., the causal agent of leaf brown spot of lettuce. Plant Pathology Bulletin 13:91-96

Liu Y, Whelen S, Hall B (1999) Phylogenetic relationships among Ascomycetes: evidence from an RNA polymerase II subunit. Mol Biol Evol 16:1799-1808

Lombard L, van der Merwe NA, Groenewald JZ, Crous PW (2015) Generic concepts in Nectriaceae. Stud Mycol 80:189-245

Maharachchikumbura SSN, Hyde KD, Gareth Jones EB, McKenzie EHC, Huang SK (2015) Towards a natural classification and backbone tree for Sordariomycetes. Fungal Divers 72:199-301

Maharachchikumbura SSN, Hyde KD, Gareth Jones EB, McKenzie EHC, Bhat JD (2016) Families of Sordariomycetes. Fungal Divers 79:1-317

Masudi S, Bonjar GHS (2012) Fulfillment of Koch's postulates for in vitro pathogenicity of Musicillium theobromae (turconi) Zare \& Z. Gams as the cause of banana cigar end rot disease. J Plant Prot Res 52:410-414

Mazzaferro L, Piñuel L, Minig M, Breccia JD (2010) Extracellular monoenzyme deglycosylation system of 7-O-linked flavonoid beta-rutinosides and its disaccharide transglycosylation activity from Stilbella fimetaria. Arch Microbiol 192:383-393

Mostert L, Groenwald JZ, Summerbell RC, Gams W, Crous PW (2006) Taxonomy and pathology of Togninia (Diaporthales) and its Phaeoacremonium anamorphs. Stud Mycol 54:1-115 
Nylander JAA (2004) MrModeltest v2. Program distributed by the author. Evolutionary Biology Centre, Uppsala University, Sweden

Perdomo H, Sutton DA, García D, Fothergill AW et al (2011) Spectrum of clinically relevant Acremonium species in the United States. J Clin Microbiol 49:243-256

Réblová M, Gams W, Seifert KA (2011) Monilochaetes and allied genera of the Glomerellales, and a reconsideration of families in the Microascales. Stud Mycol 68:163-191

Rehner SA, Buckley E (2005) A Beauveria phylogeny inferred from nuclear ITS and EF-1alpha sequences: evidence for cryptic diversification and links to Cordyceps teleomorphs. Mycologia 97:84-98

Rehner SA, Samuels GJ (1995) Molecular systematics of the Hypocreales: a teleomorph gene phylogeny and the status of their anamorphs. Can $\mathrm{J}$ Bot 73:S816-S823

Ronquist F, Huelsenbeck JP (2003) MrBayes 3: Bayesian phylogenetic inference under mixed models. Bioinformatics 19:1572-1574

Ronquist F, Teslenko M, van der Mark P, Ayres DL (2012) MrBayes 3.2: efficient bayesian phylogenetic inference and model choice across a large model space. Syst Biol 61:539-542

Schoch CL, Sung GH, López-Giráldez F, Townsend JP et al (2009) The Ascomycota tree of life: a phylum wide phylogeny clarifies the origin and evolution of fundamental reproductive and ecological traits. Syst Biol 58:224239

Seifert KA (1985) A monograph of Stilbella and some allied Hyphomycetes. Stud Mycol 27:1-235 
Shenoy BD, Jeewon R, Wu WP, Bhat DJ, Hyde KD (2006) Ribosomal and $R P B 2$ DNA sequence analyses suggest that Sporidesmium and morphologically similar genera are polyphyletic. Mycol Res 110:916-928

Sigler L, Zuccaro A, Summerbell RC, Mitchell JI, Paré JA (2004) Acremonium exuviarum sp. nov., a lizard-associated fungus with affinity to Emericellopsis. Stud Mycol 50:409-413

Spatafora JW, Sung GH, Johnson D, Hesse C et al (2006) A five-gene phylogeny of Pezizomycotina. Mycologia 98:1018-1028

Spatafora JW, Sung GH, Sung JM, Hywel-Jones NL, White JF Jr (2007) Phylogenetic evidence for an animal pathogen origin of ergot and the grass endophytes. Mol Ecol 16:1701-1711

Spegazzini C (1910) Mycetes Argentinenses (Series V). An. Mus. nac. Hist. nat. B. Aires. 20:329-467

Summerbell RC (2003) Ascomycetes: Aspergillus, Fusarium, Sporothrix, Piedraia and their relatives. In: Howard DH (ed.) Pathogenic fungi in humans and animals, 2nd edn. Marcel Dekker, New York, pp 237-498

Summerbell RC, Gueidan C, Schroers HJ, Hoog GS de et al (2011) Acremonium phylogenetic overview and revision of Gliomastix, Trichothecium and Sarocladium. Stud Mycol 68:139-162

Tamura K, Stecher G, Peterson D, Filipski A, Kumar S (2013) MEGA 6: Molecular Evolutionary Genetics Analysis version 6.0. Mol Biol Evol 30:27252729

Thompson JD, Higgins DG, Gibson TJ (1994) CLUSTAL W: improving the sensitivity of progressive multiple sequence alignment through sequence 
weighting, position-specific gap penalties and weight matrix choice. Nucleic Acids Res 22:4673-4680

Vilgalys R, Hester M (1990) Rapid genetic identification and mapping of enzymatically amplified ribosomal DNA from several Cryptococcus species. J Bacteriol 172: 4238-4246

Vilgalys R, Sun BL (1994) Ancient and recent patterns of geographic speciation in the oyster mushroom Pleurotus revealed by phylogenetic analysis of ribosomal DNA sequences. Proc Natl Acad Sci 91(10):4599-4603

Weisenborn JLF, Kirschner R, Piepenbring M (2010) A new darkly pigmented and keratinolytic species of Acremonium (Hyphomycetes) with relationship to the Plectosphaerellaceae from human skin and nail lesions in Panama. Nova Hedwigia 90:457-468

White TJ, Bruns T, Lee J, Taylor SB (1990) Amplification and direct sequencing of fungal ribosomal RNA genes for phylogenetics. In: Innis MA, Gelfand DH, Sninsky JJ, White TJ (eds) PCR Protocols: a guide to methods and applications. Academic Press, San Diego, pp 315-322

Zare R, Gams W, Starink-Willemse M, Summerbell RC (2007) Gibellulopsis, a suitable genus for Verticillium nigrescens, and Musicillium, a new genus for $V$. theobromae. Nova Hedwigia 85:463-489

Zuccaro A, Summerbell RC, Gams W, Schoers HJ, Mitchell JI (2004) A new Acremonium species associated with Fucus spp., and its affinity with a phylogenetically distinct marine Emericellopsis clade. Stud Mycol 50:283-297 